Supporting Information for

\title{
A geomorphic-process-based cellular automata model of colluvial wedge morphology and stratigraphy
}

\author{
H. J. Gray ${ }^{1}$, C. B. DuRoss' ${ }^{2}$ S. R. Nicovich ${ }^{3}$, and R. D. Gold ${ }^{2}$ \\ ${ }^{1}$ US Geological Survey, Geosciences and Environmental Change Science Center, Lakewood CO \\ 2US Geological Survey, Natural Hazards Science Center, Golden, CO \\ ${ }^{3}$ US Bureau of Reclamation, Technical Services Center, Lakewood CO
}

\section{Contents of this file}

Text S1 to S2

Figures S1 to S43

\section{Introduction}

This supplemental material consists of Figures for the parameter space exploration in the main text and testing/evaluation of the cell size assumption using in the model.

\section{Text S1. Parameter Space Exploration}

In this section, we provide figures showing the results of the parameter space exploration for the model presented in the main text of the paper. Each figure shows a 4 by 4 matrix of a plot of a model run with each plot labeled alphabetically with a letter from $A$ to $P$. The values for the soil disturbance rate $(D)$ and soil production rate $\left(W_{-} 0\right)$ are located in a text box in the upper lefthand corner of the plot. The value for the lateral collapse rate (LCR) and fault dip are given in the title of the figure. Note that the text within the squares in Figure 9 and 10 in the main text reference the plots by $\mathrm{S}$ [supplemental figure number][figure subplot letter]. For example, S3O in Figure 9 is translated as Supplemental Figure S3, subplot O.

Figures S1 through S8 show the overall morphology and cell facies classification of a model run as described in the main text. Figures S9-S16 show the values for Transport Index. Figures S17-S24 present values for the overall linear distance a cell has travelled. Figure S25-S32 demonstrate the transport time value for each sediment cell. Finally, Figures S33-S40 show the average transport velocity value for each sediment cell. 


\section{Text S2. Scatter plots of cell transport characteristics and cell facies classification}

In the main text, we describe how scatter plots allow us to analyze the grouping of sediment cells by their transport characteristics. These groupings are not coded into the model and arise as a result of the ensemble effects of sediment transport. We interpret these groupings into analogs for facies described in the colluvial wedge conceptual model. Figures S41-S48 show scatterplots of Transport Time versus Transport Index. Figures S49-S56 show scatterplots of Average Transport Velocity versus Transport Index. Finally, Figures S57-S64 show scatterplots of Transport Time versus the overall linear distance of transport. See main text for discussion.

\section{Text S3. Cell Size Effects}

To validate our use of the $2.5 \mathrm{~cm}$ cell size, we examined the effects of changing cell size and if it would affect our interpretations. We ran four test scenarios with a $10 \mathrm{~cm}, 5 \mathrm{~cm}$ and $2.5 \mathrm{~cm}$, and examined the resulting plots of colluvial wedge morphology, transport index, velocity, and facies classification for the 60-degree and 90-degree endmembers (Figures S42 and S43). The results of the cell size show a change in resolution between model runs for the colluvial wedge morphology, the transport index, and velocity. However, the same general spatial patterns are present between model runs with the varying cell size. Model runs with larger cell sizes appear more 'blocky,' whereas smaller cell sizes appear more 'smooth.' There does not appear to be a significant difference in the overall form of the morphology, transport index and velocity. This greater resolution comes at a cost as the computational time for the 2.5 centimeter cell size model run takes half an hour as opposed to the $\sim 2$ mins for a $5 \mathrm{~cm}$ cell size model run and $\sim 1 \mathrm{~min}$ for the $10 \mathrm{~cm}$ cell size run. Although note that at the higher ends of the parameter ranges, computational times rise significantly. For this reason, we used the $5 \mathrm{~cm}$ cell size range as a compromise between resolution and computational costs.

\section{Figure Captions}

Figures S1-S8: Plot of cell states for each model run in the parameter space exploration. Cell facies analogs are shown with indicated colors.

Figures S9-S16: Results of calculating the Transport Index for sediment cells for each model run in the parameter space exploration.

Figures S17-S24: Plots of the linear distance of displacement for each sediment cell for every model run

Figures S25-S32: Compilation of the transport time for each sediment cell following methods in the main text. 
Figures S33-S40: Compilation of the average transport velocity for each sediment cell following methods in the main text.

Figures S41-S48: Scatterplots of Transport Time versus Transport Index.

Figures S49-S56: Scatterplots of Average Transport Velocity versus Transport Index.

Figures S57-S64: Scatterplots of Transport Time versus the overall linear distance of transport.

Figure S66: Results of varying the cell size on the $60^{\circ}$ fault model run.

Figure S67: Results of varying the cell size on the $90^{\circ}$ fault model run. 
Figure S4: Wedge Morpho-stratigraphy Sensitivity; 60-degree Fault; Lateral Collapse Rate $=1$. e-11
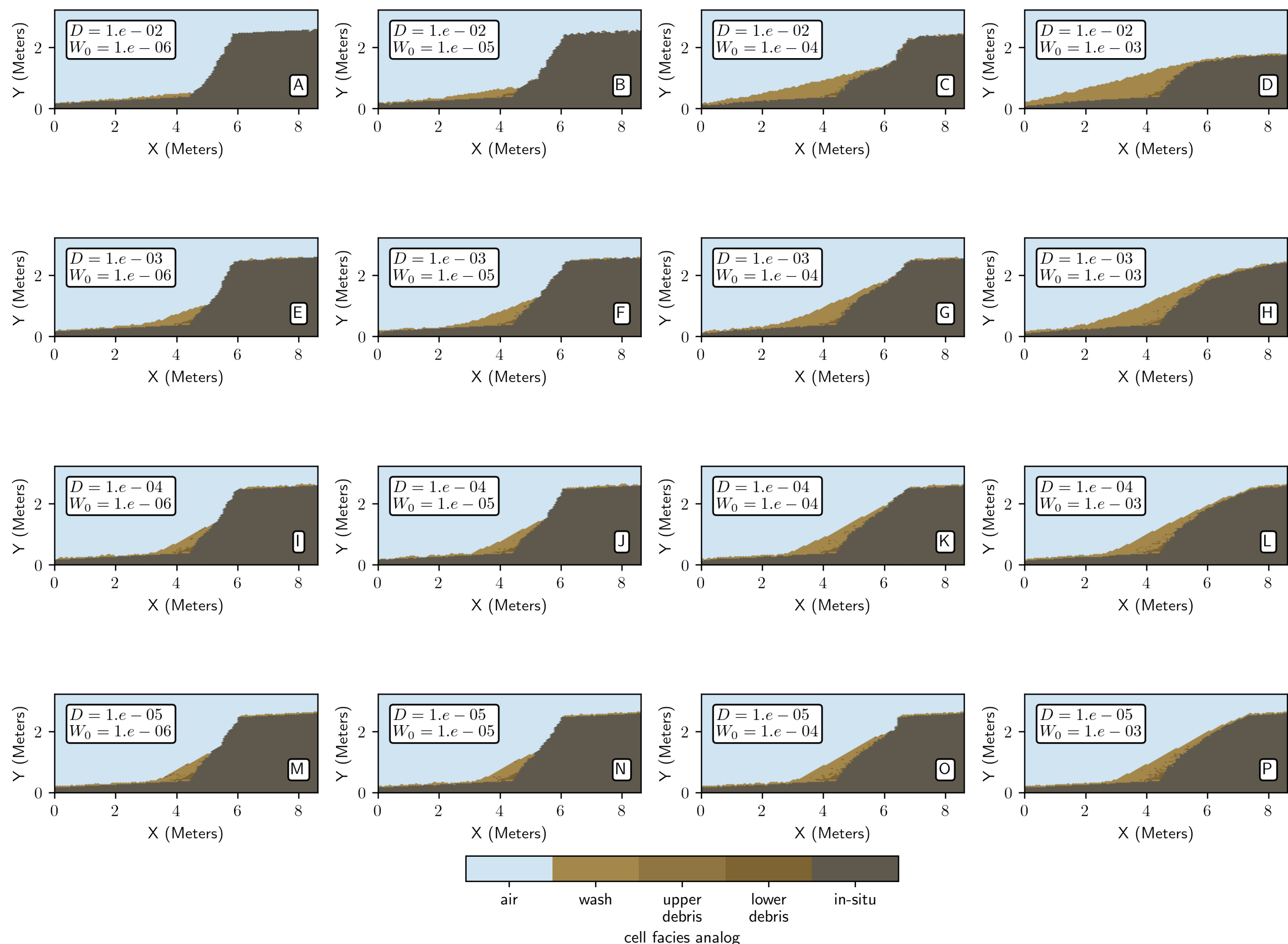

cell facies analog 
Figure S8: Wedge Morpho-stratigraphy Sensitivity; 90-degree Fault; Lateral Collapse Rate =1.e-11
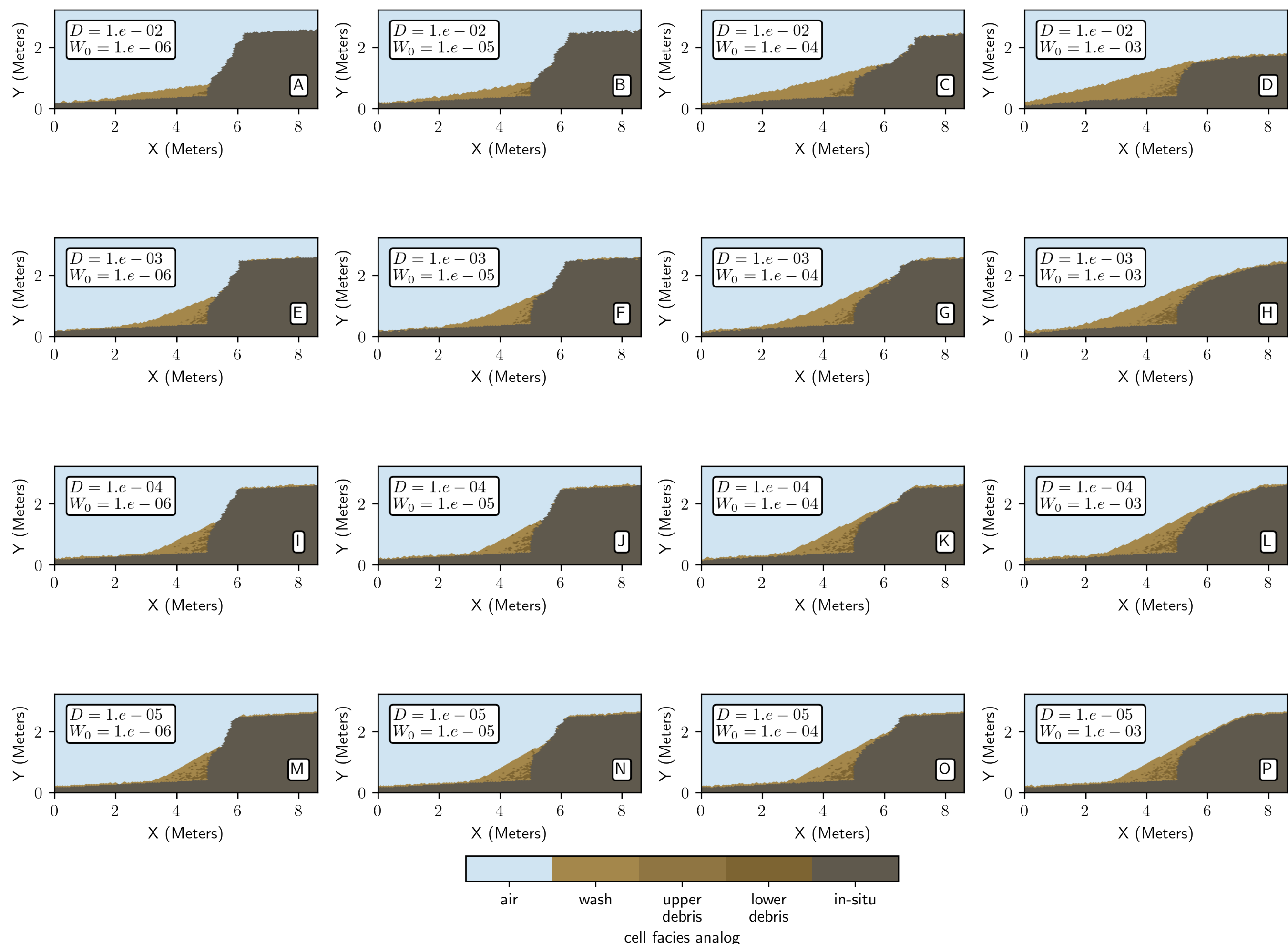

cell facies analog 
Figure S9: Transport Index Sensitivity; 60-degree Fault; Lateral Collapse Rate $=1$. e-03
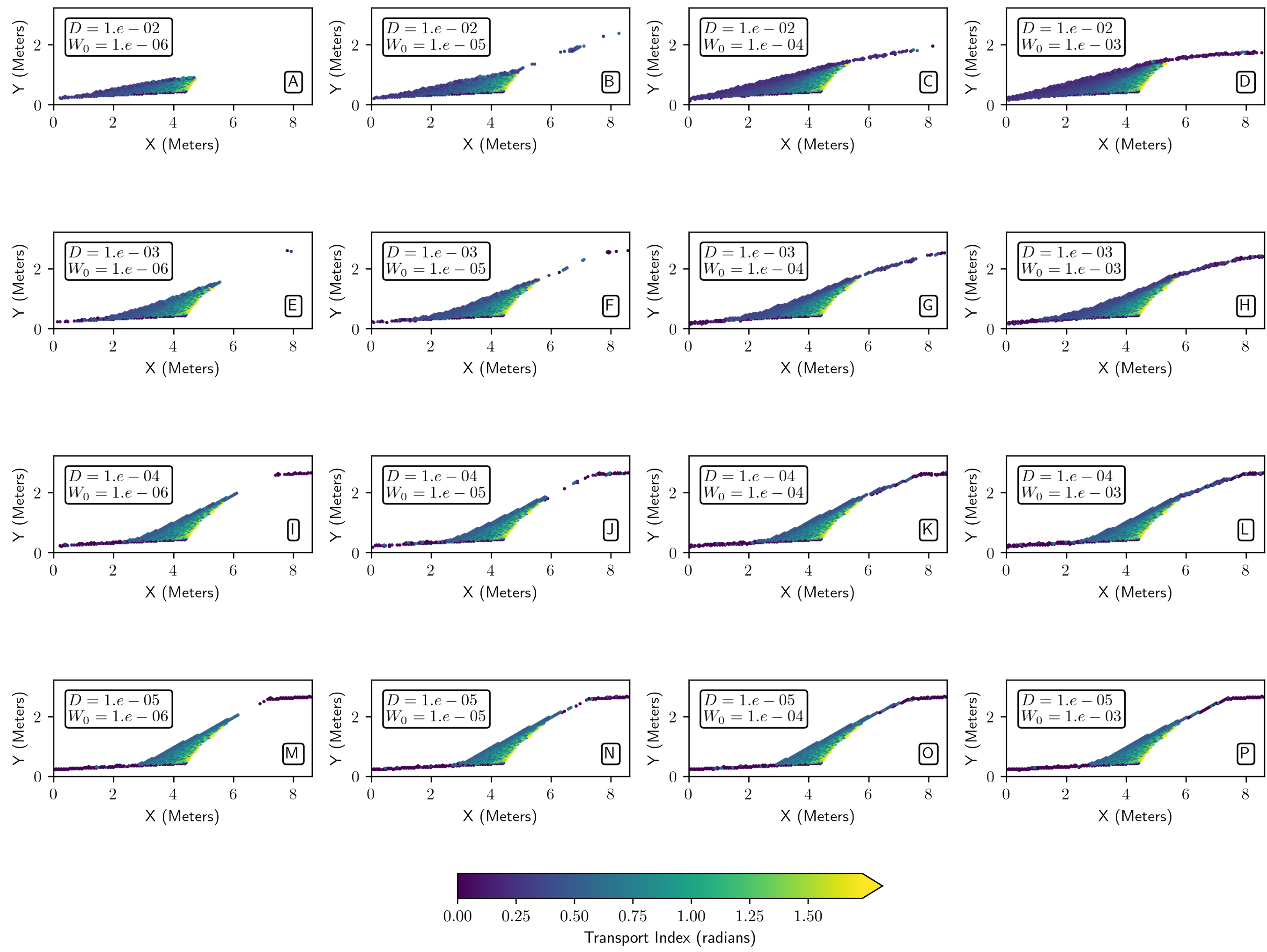
Figure S10: Transport Index Sensitivity; 60 -degree Fault; Lateral Collapse Rate $=1$. e-05
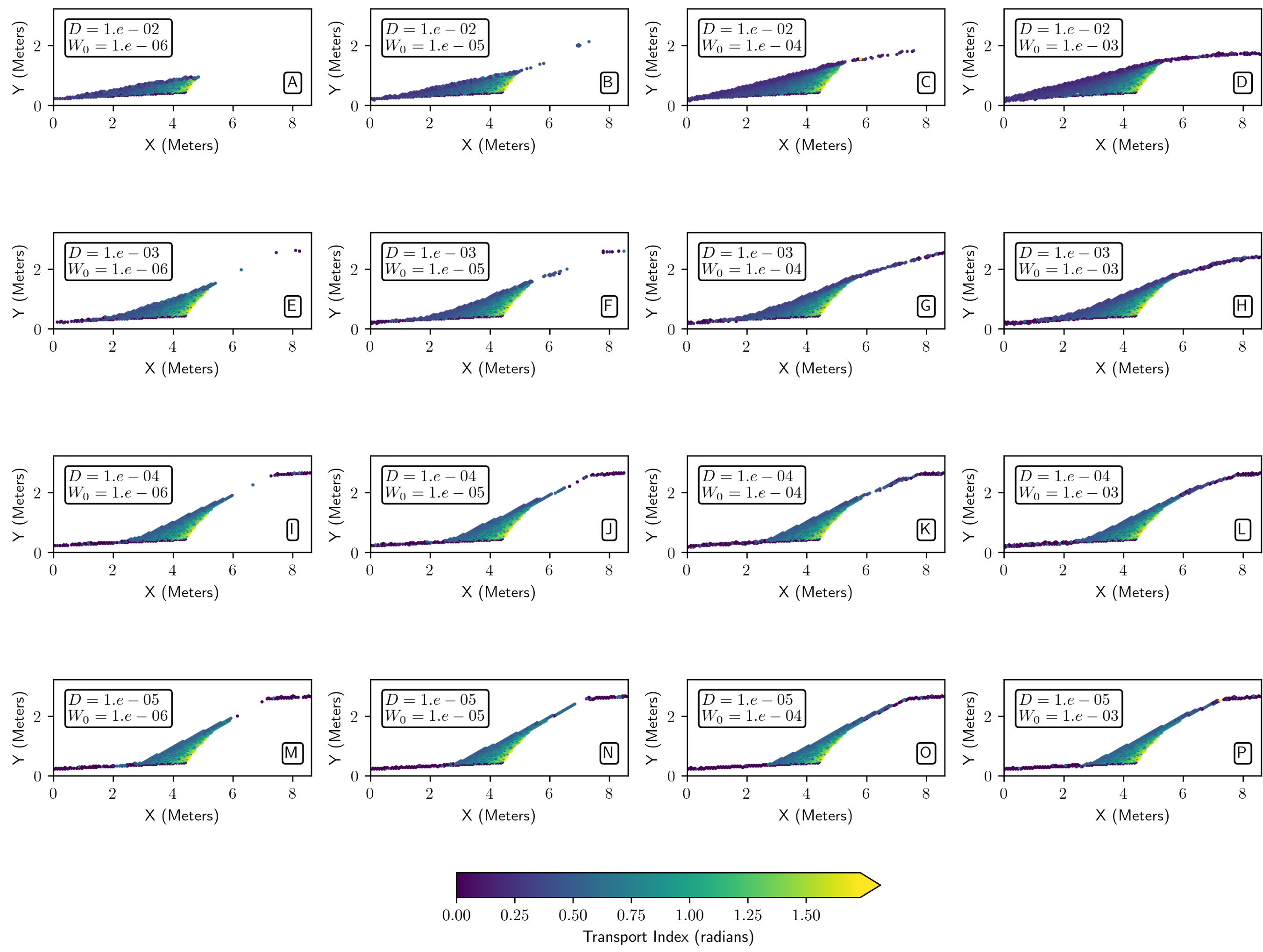
Figure S11: Transport Index Sensitivity; 60 -degree Fault; Lateral Collapse Rate $=1$. e-09
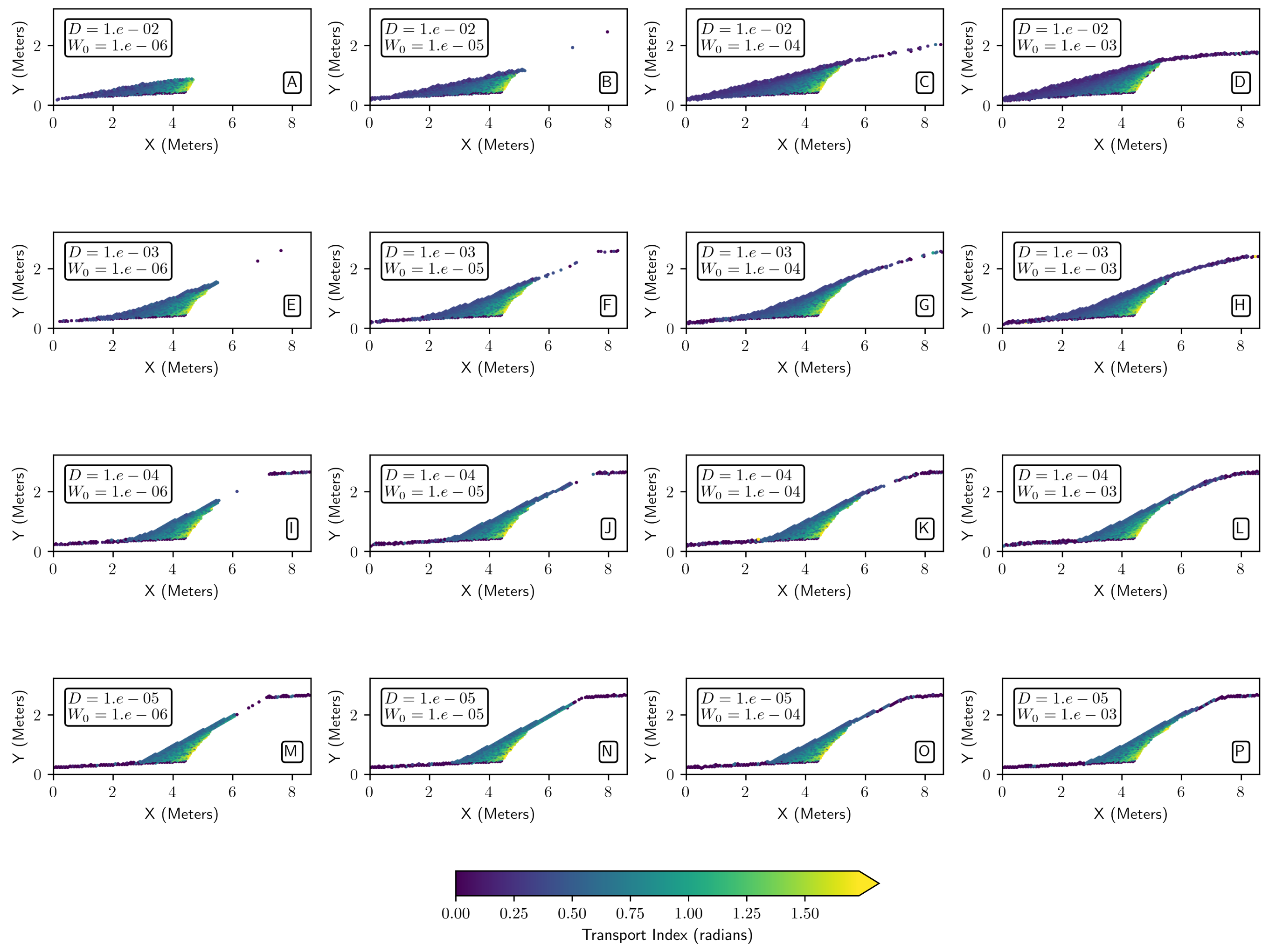
Figure S13: Transport Index Sensitivity; 90-degree Fault; Lateral Collapse Rate $=1$. e-03
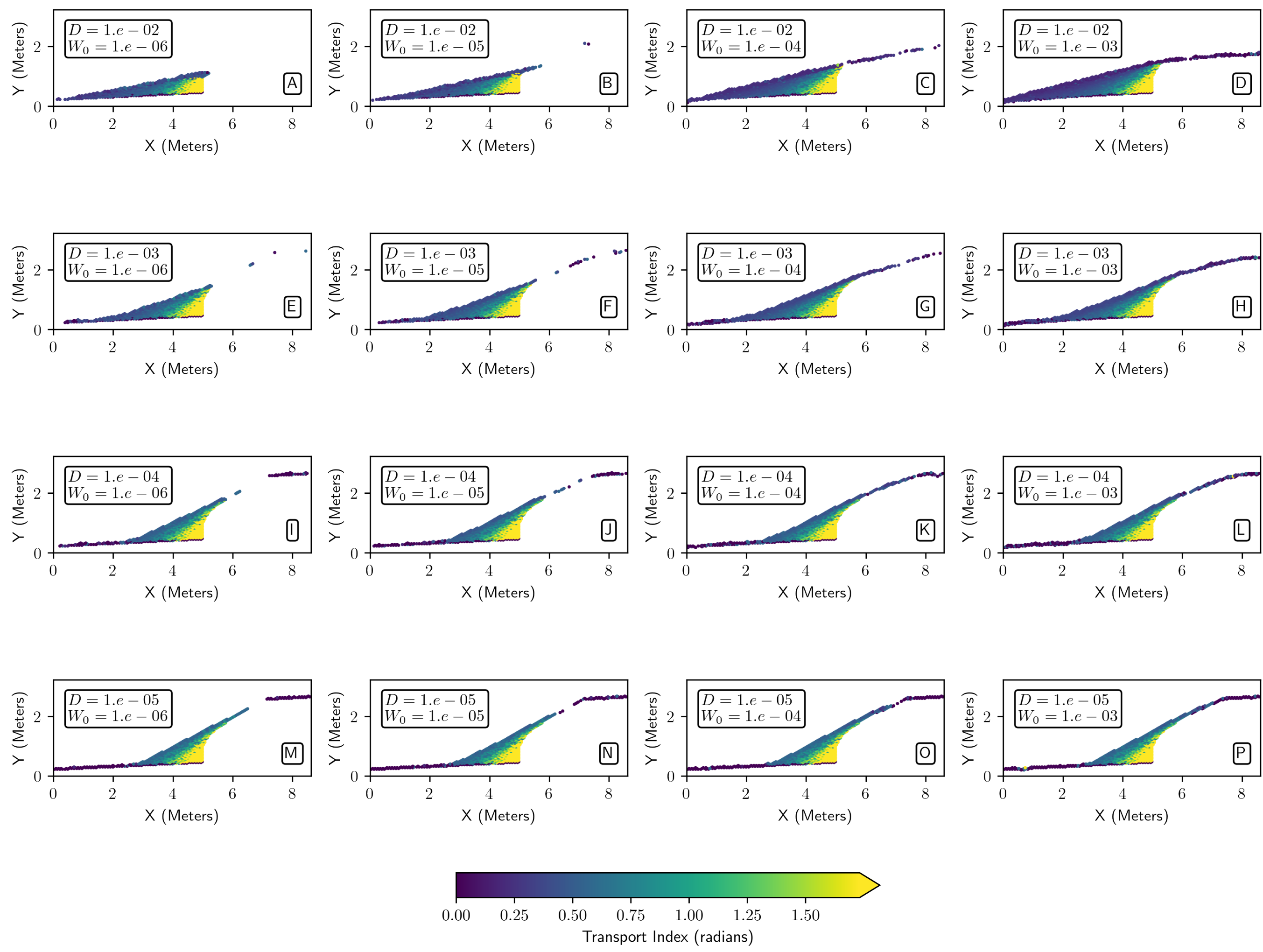
Figure S20: Linear Distance Sensitivity; 60-degree Fault; Lateral Collapse Rate $=1$.e-11
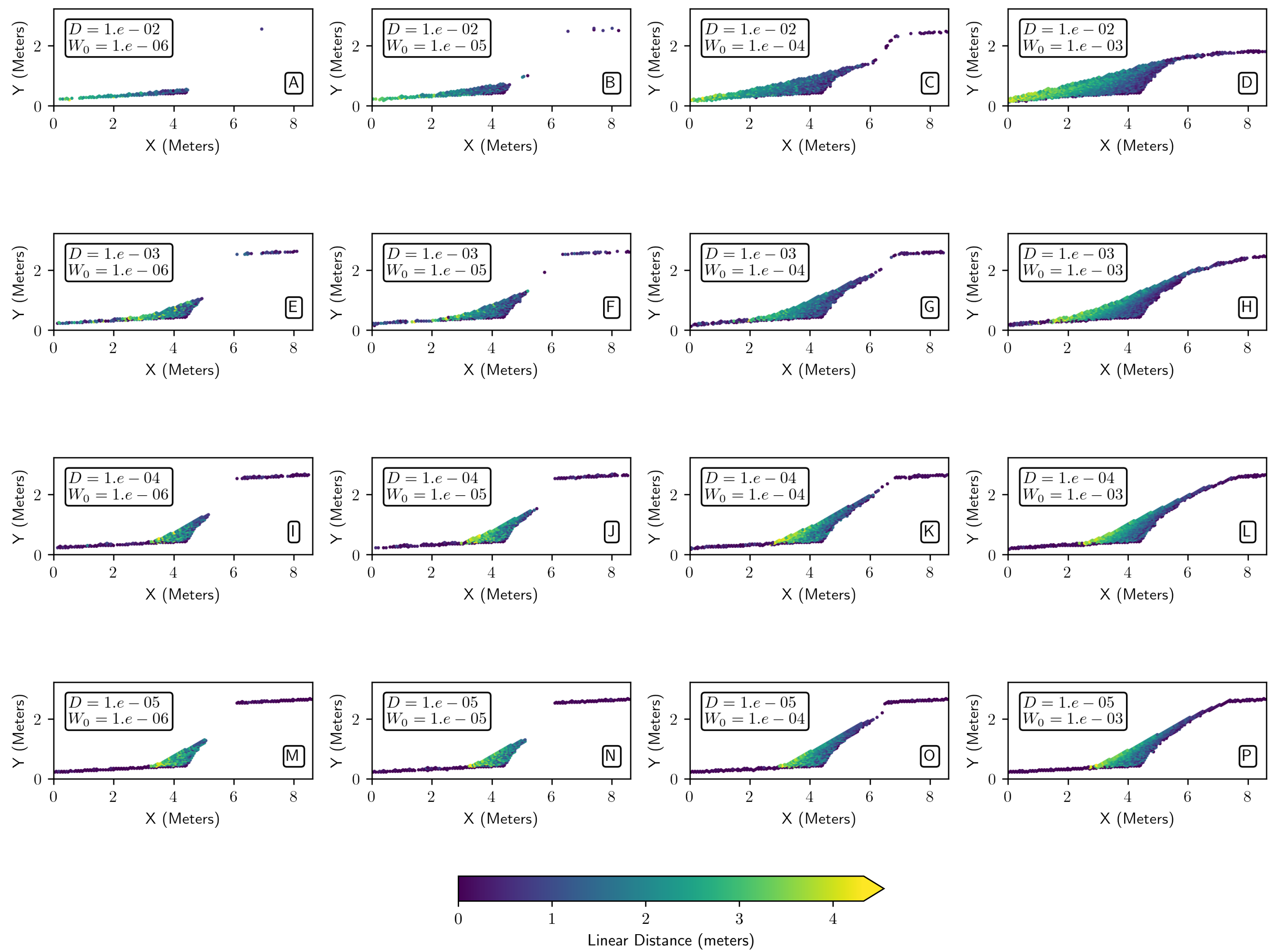
Figure S21: Linear Distance Sensitivity; 90-degree Fault; Lateral Collapse Rate $=1$. e-03
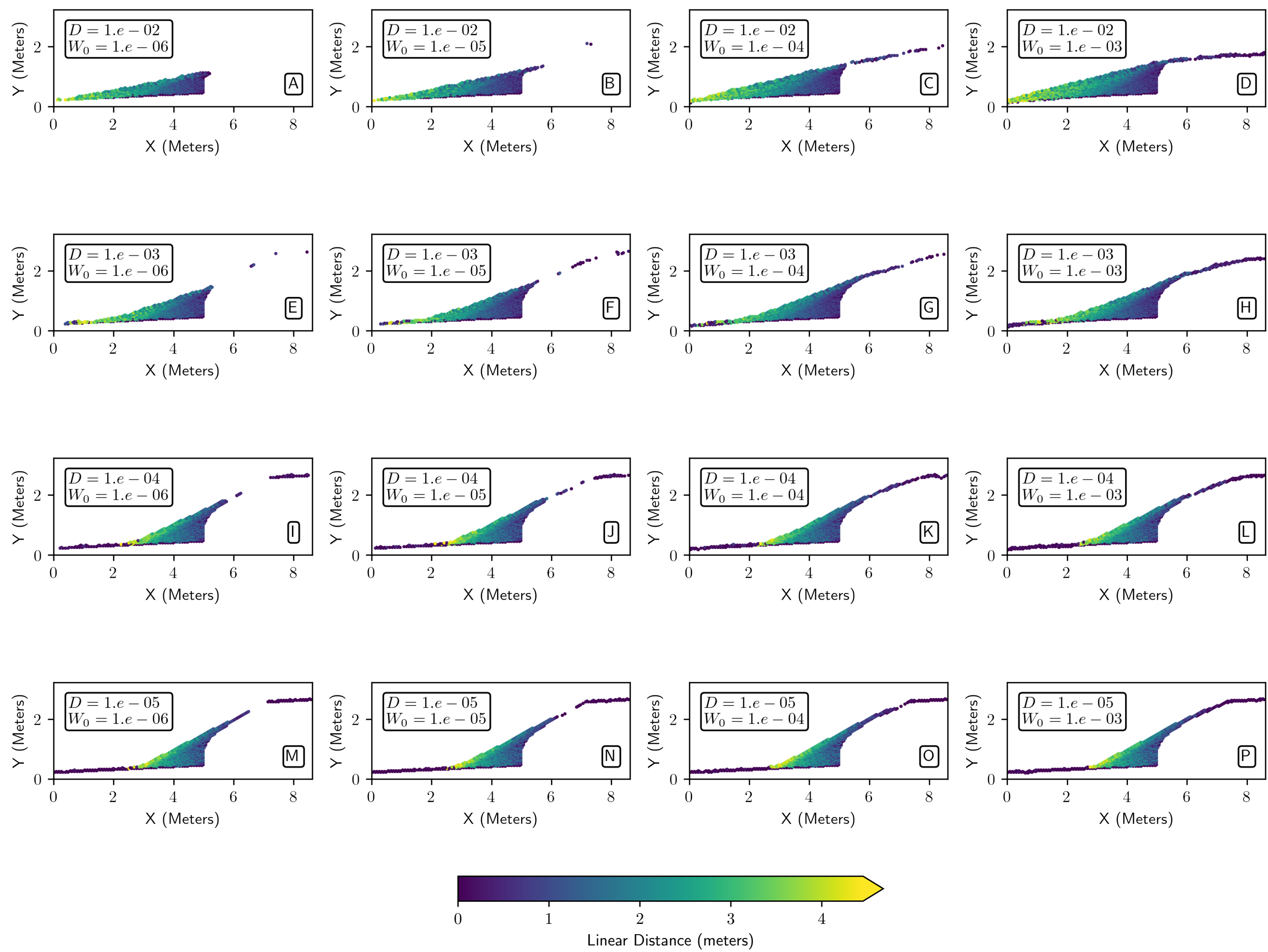
Figure S22: Linear Distance Sensitivity; 90-degree Fault; Lateral Collapse Rate $=1$.e-05
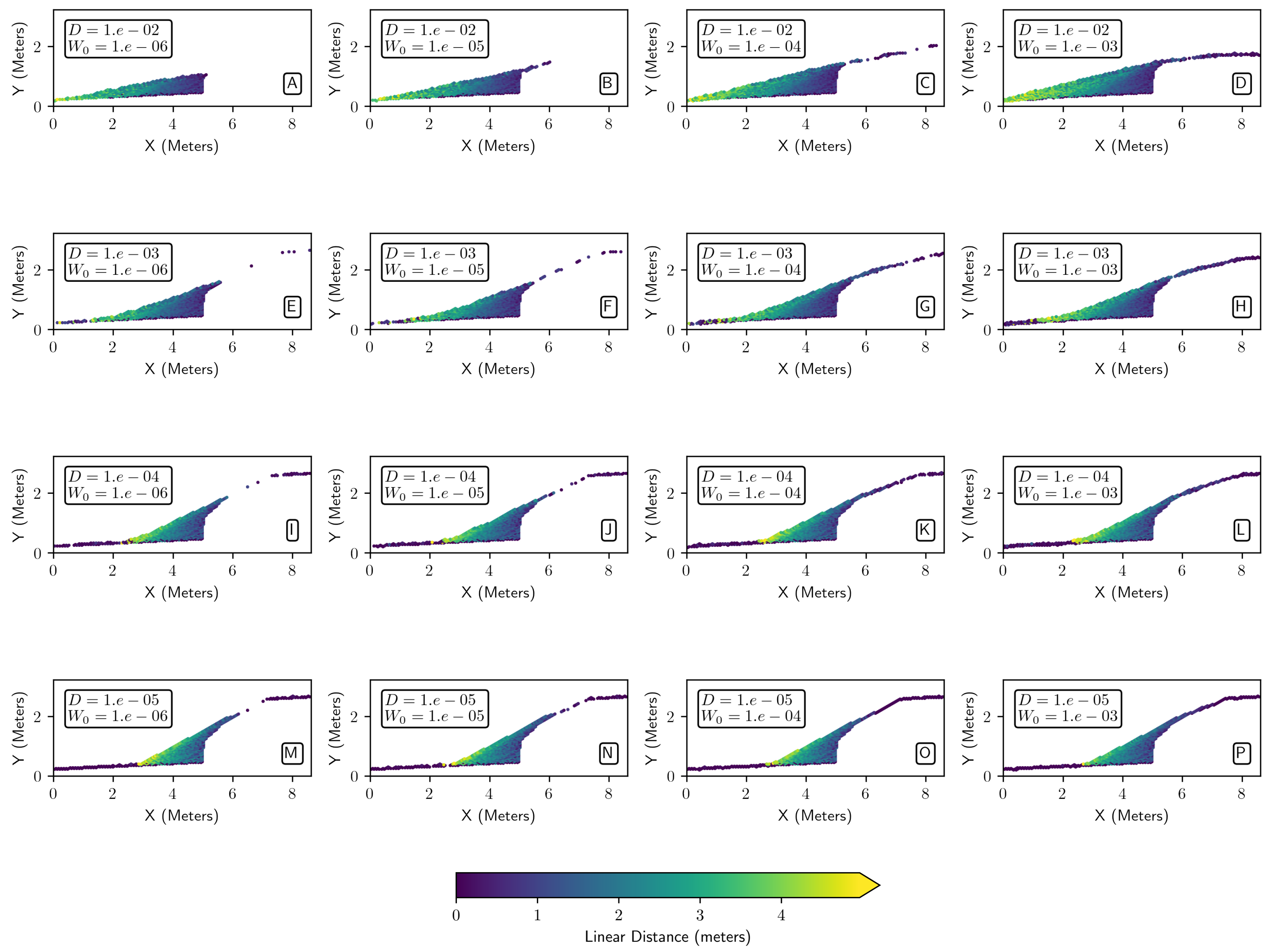
Figure S23: Linear Distance Sensitivity; 90-degree Fault; Lateral Collapse Rate $=1$.e-09
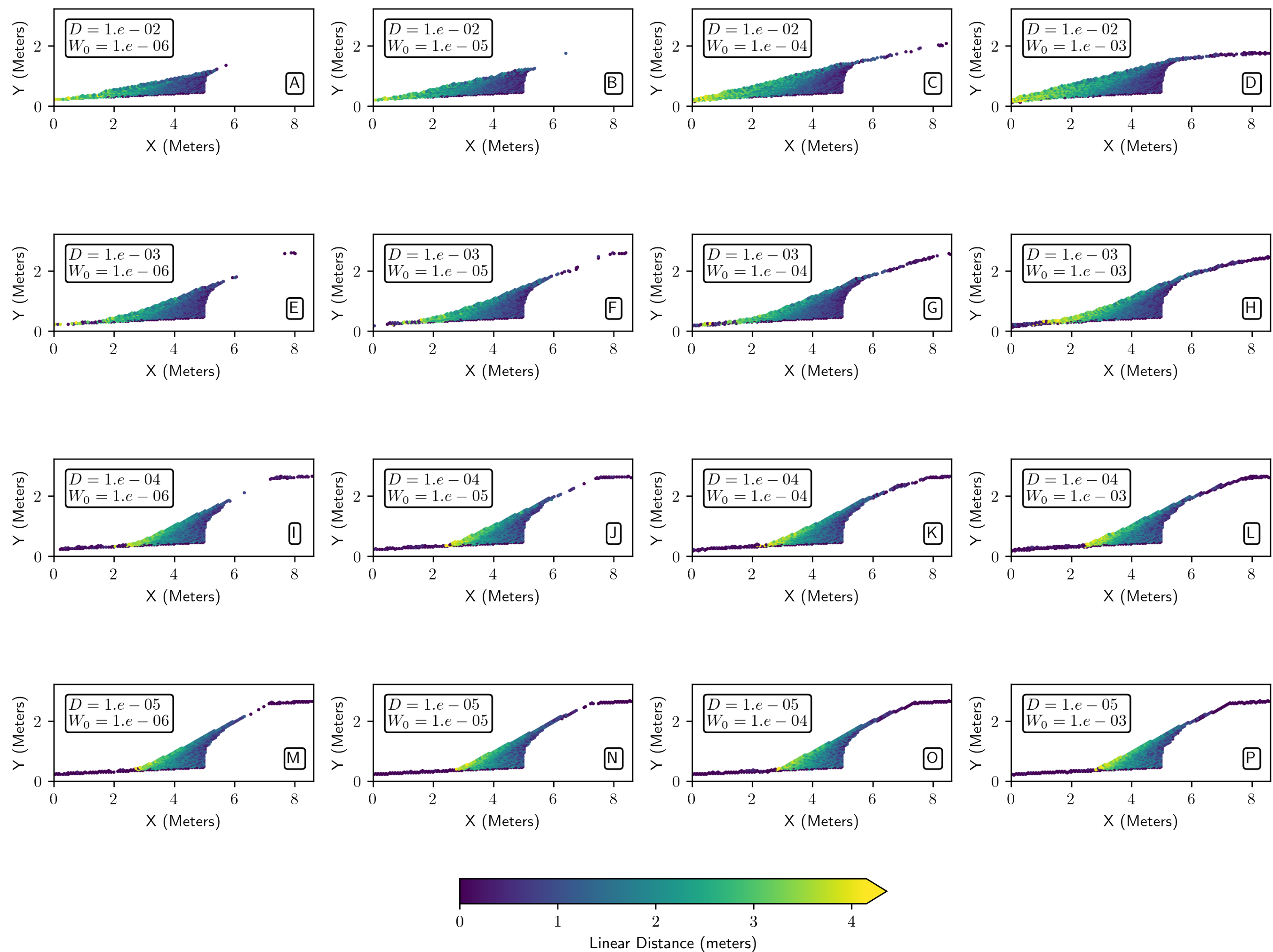
Figure S25: Transport Time Sensitivity; 60 -degree Fault; Lateral Collapse Rate $=1$. e-03
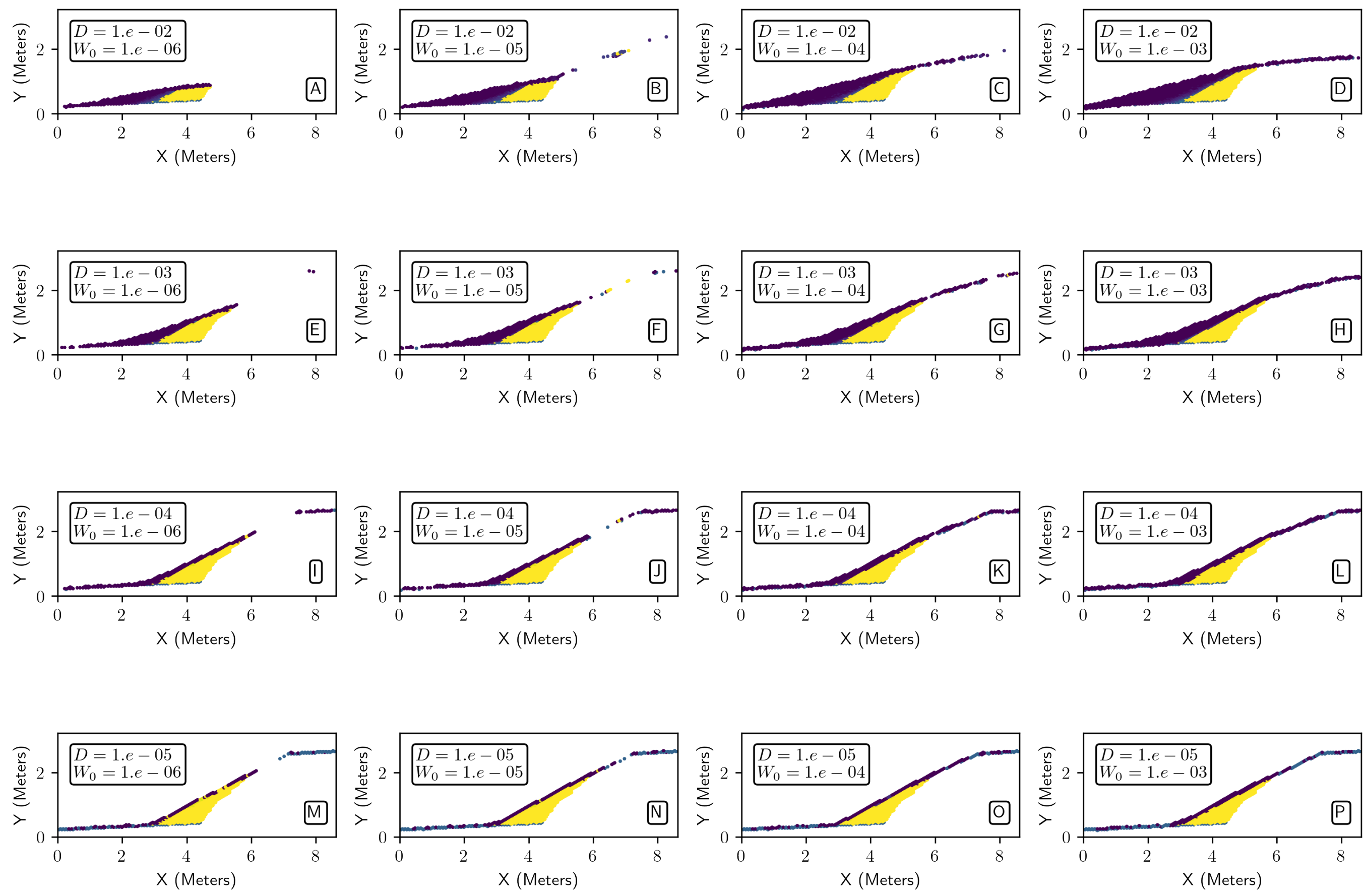

$\begin{array}{llrl}1 \text { Hour } & 1 \text { Day } 1 \text { Year } 100 \text { Years } \\ & \text { Transport Time (years) } & \end{array}$ 
Figure S26: Transport Time Sensitivity; 60-degree Fault; Lateral Collapse Rate $=1$. e-05
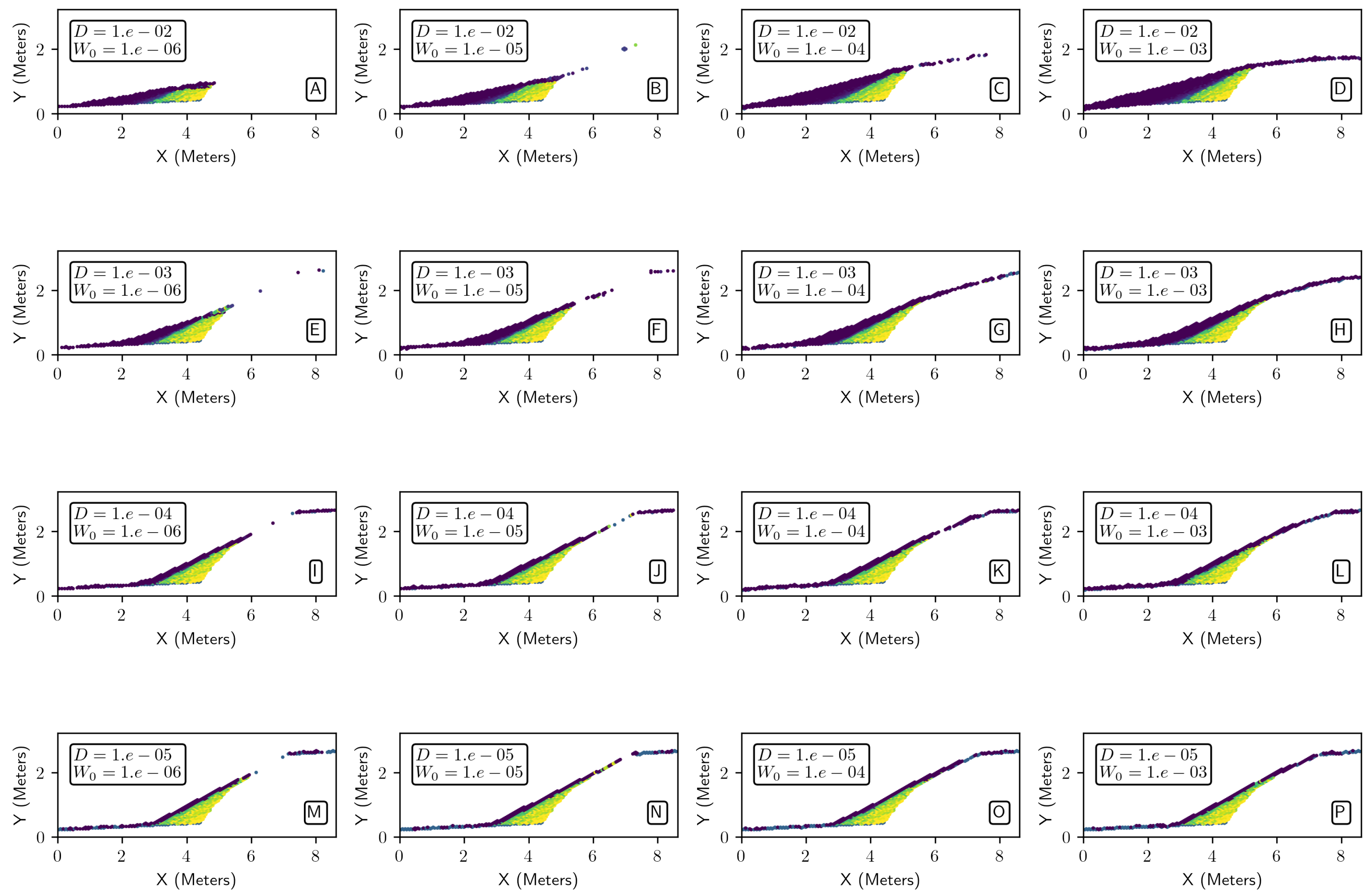

$\begin{array}{llrl}1 \text { Hour } & 1 \text { Day } 1 \text { Year } 100 \text { Years } \\ & \text { Transport Time (years) } & \end{array}$ 
Figure S27: Transport Time Sensitivity; 60 -degree Fault; Lateral Collapse Rate $=1$.e-09
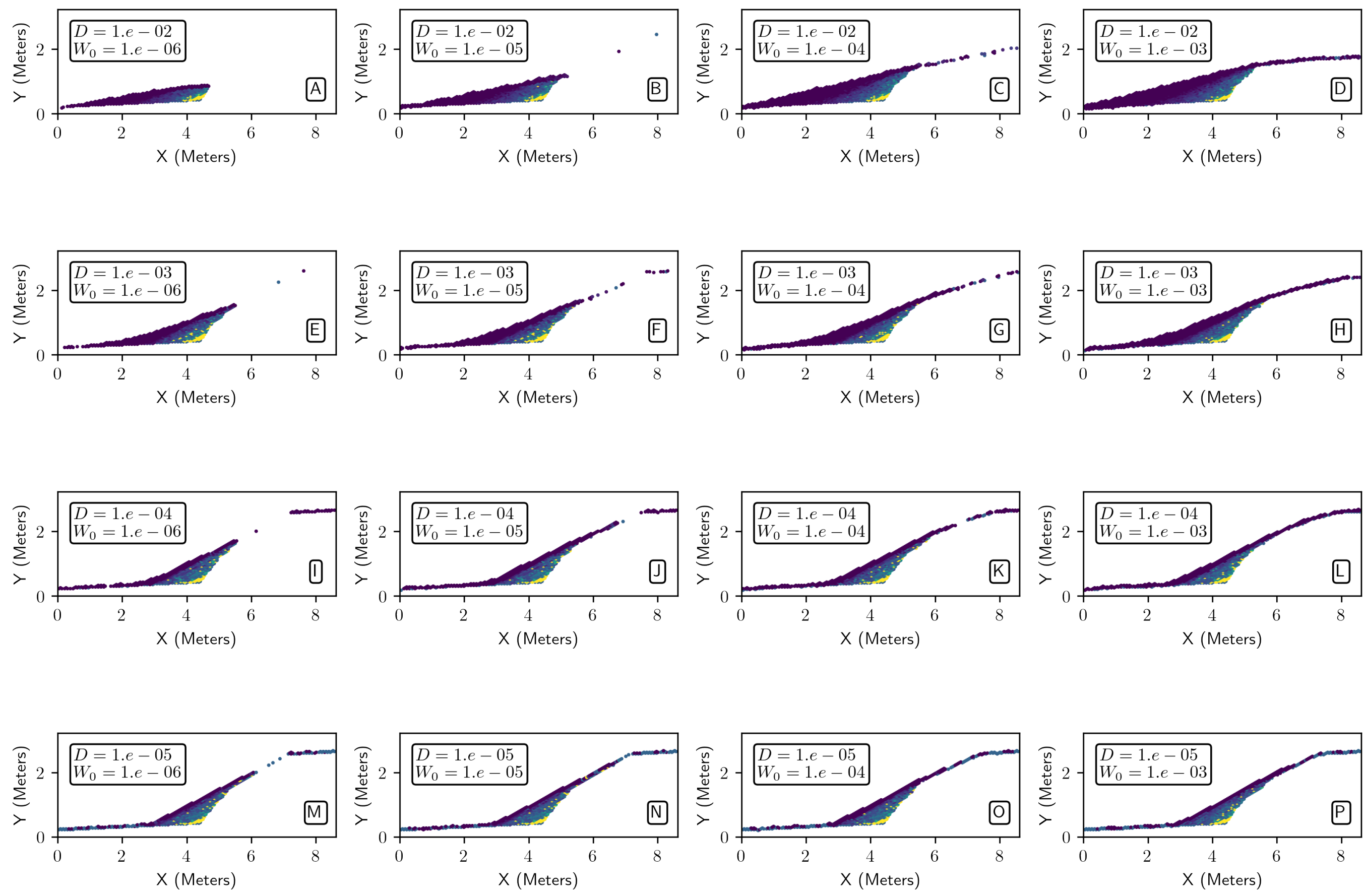

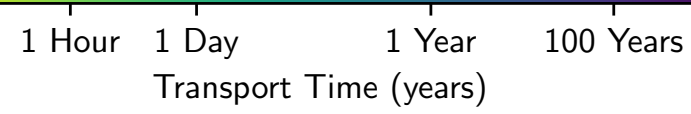


Figure S28: Transport Time Sensitivity; 60 -degree Fault; Lateral Collapse Rate $=1$. e- 11
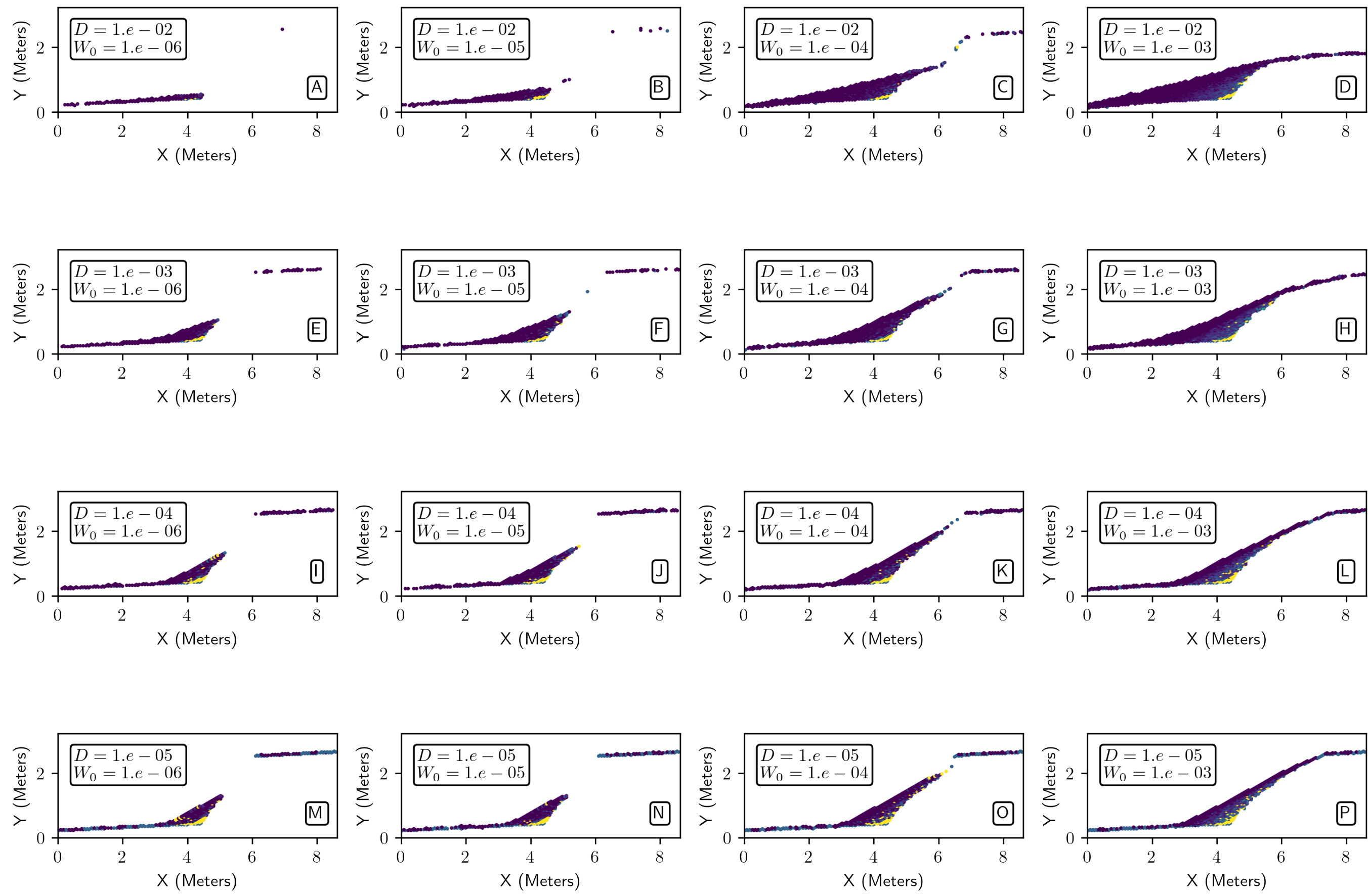
Figure S29: Transport Time Sensitivity; 90-degree Fault; Lateral Collapse Rate $=1$. e-03
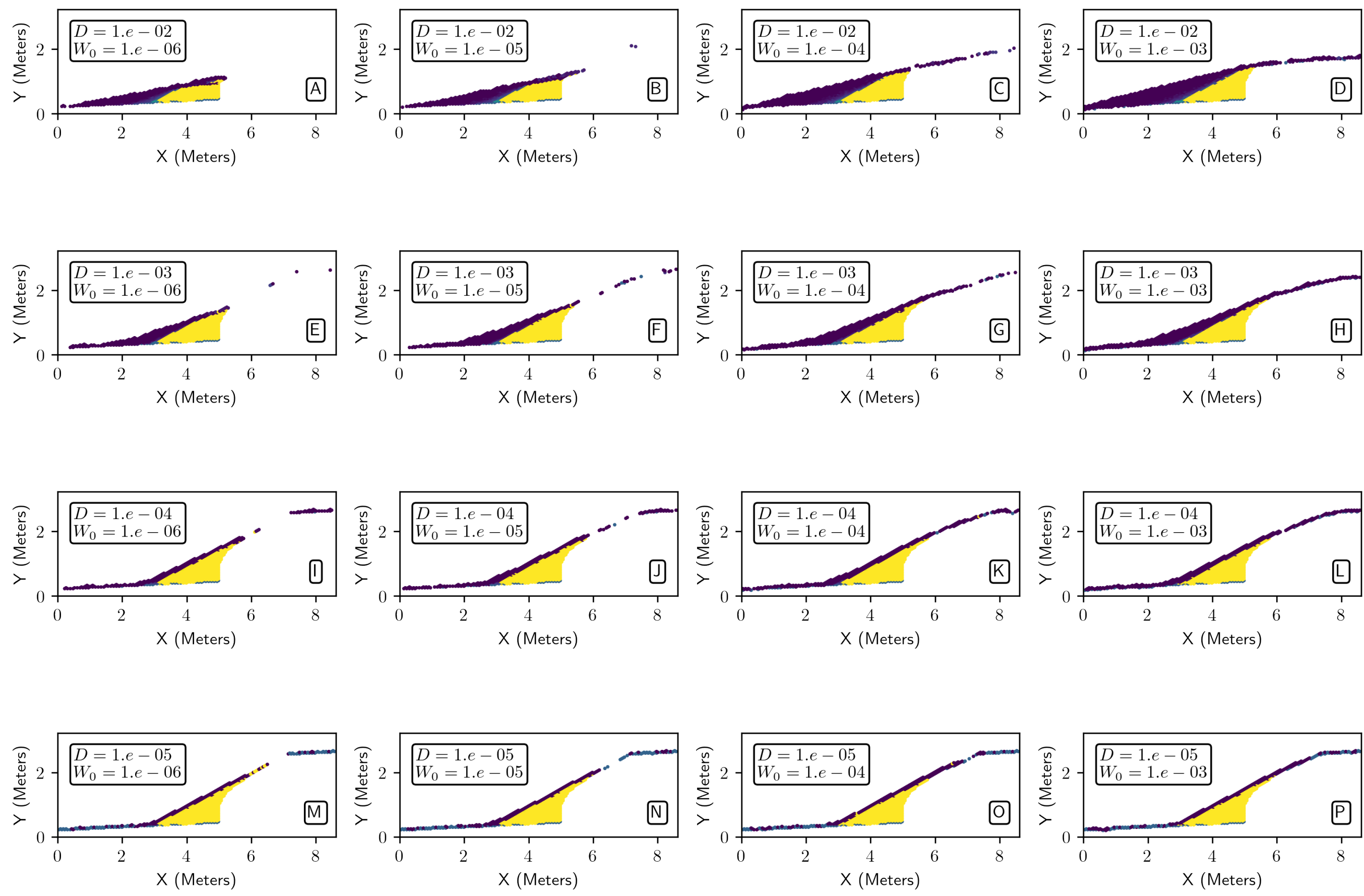

$\begin{array}{llrl}1 \text { Hour } & 1 \text { Day } 1 \text { Year } 100 \text { Years } \\ & \text { Transport Time (years) } & \end{array}$ 
Figure S30: Transport Time Sensitivity; 90-degree Fault; Lateral Collapse Rate $=1 . \mathrm{e}-05$
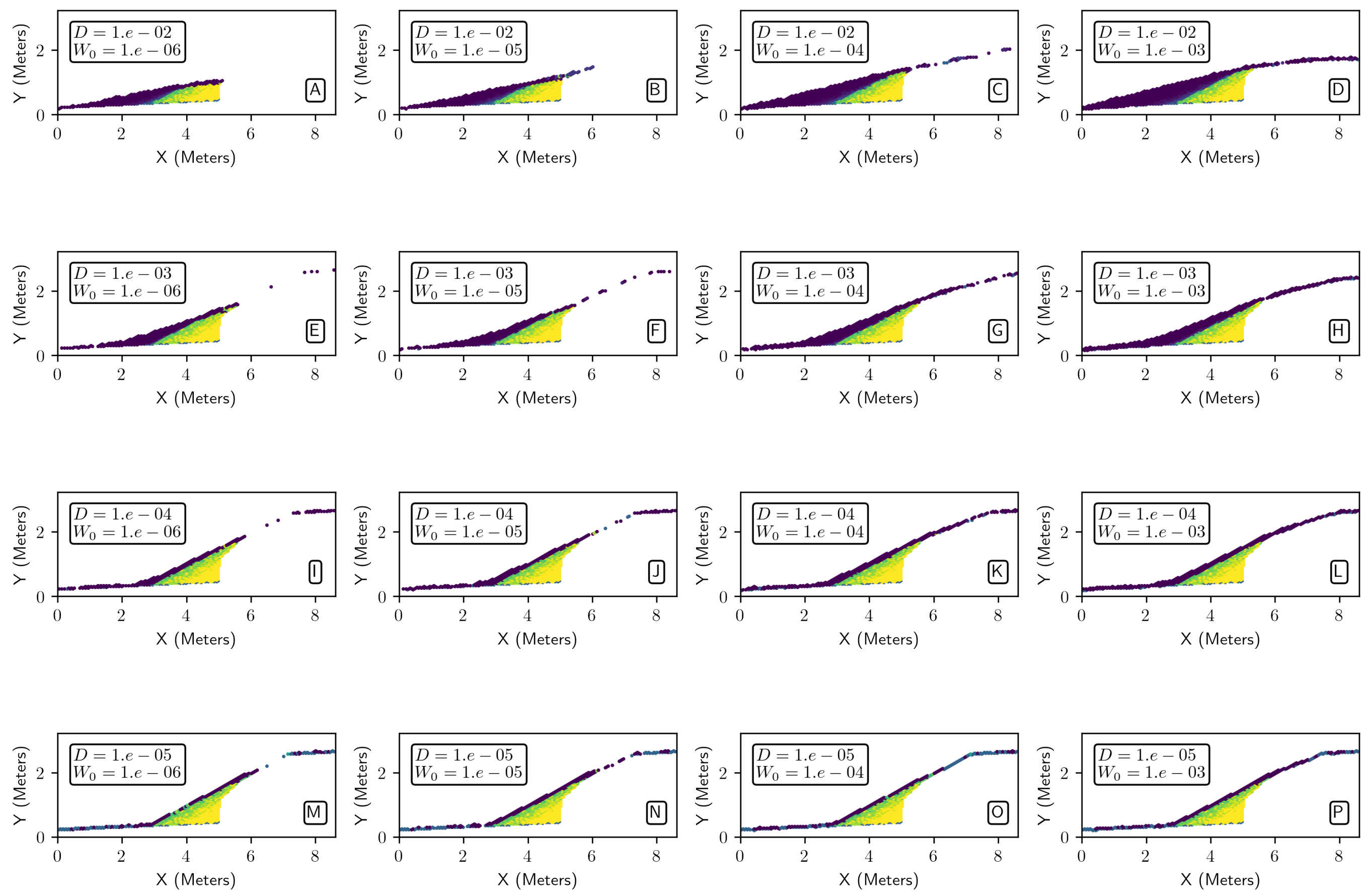

$\begin{array}{llrl}1 \text { Hour } & 1 \text { Day } 1 \text { Year } 100 \text { Years } \\ & \text { Transport Time (years) } & \end{array}$ 
Figure S31: Transport Time Sensitivity; 90-degree Fault; Lateral Collapse Rate $=1$.e-09
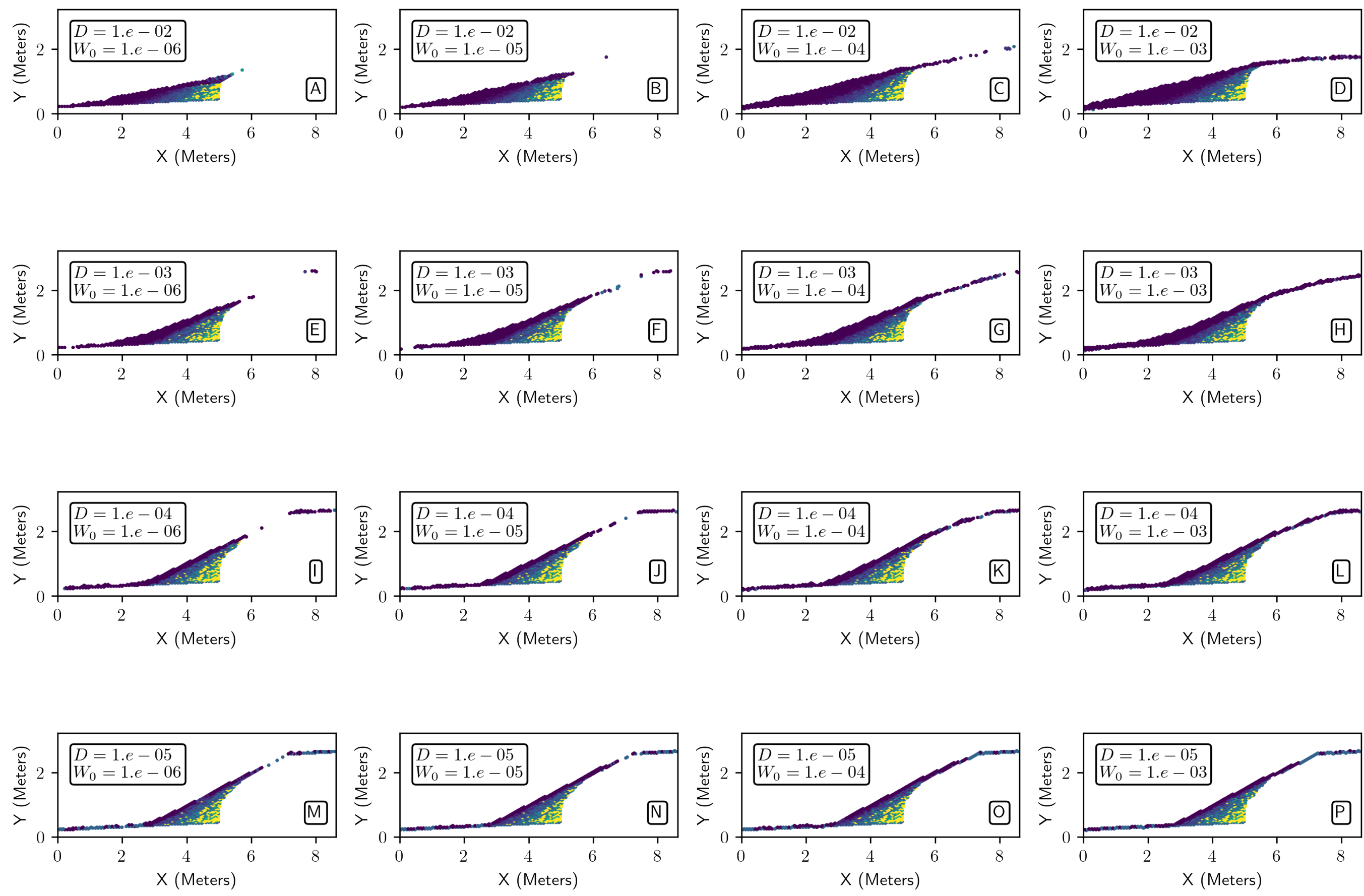

$\begin{array}{llrl}1 \text { Hour } & 1 \text { Day } 1 \text { Year } 100 \text { Years } \\ & \text { Transport Time (years) } & \end{array}$ 
Figure S32: Transport Time Sensitivity; 90-degree Fault; Lateral Collapse Rate $=1$. e-11
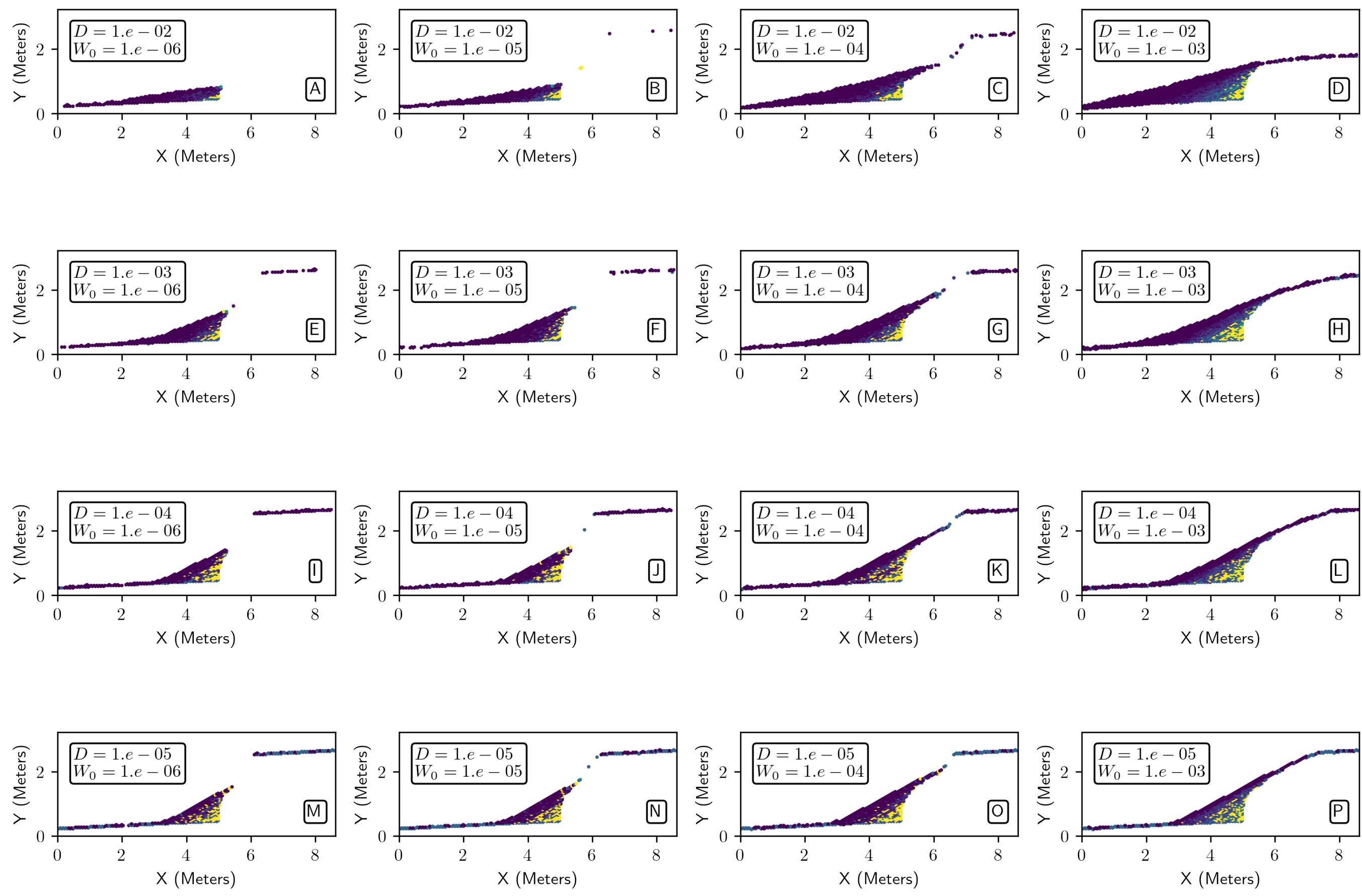

$\begin{array}{llrl}1 \text { Hour } & 1 \text { Day } & 1 \text { Year } & 100 \text { Years } \\ & \text { Transport Time (years) } & \end{array}$ 
Figure S33: Transport Velocity Sensitivity; 60-degree Fault; Lateral Collapse Rate $=1$.e-03
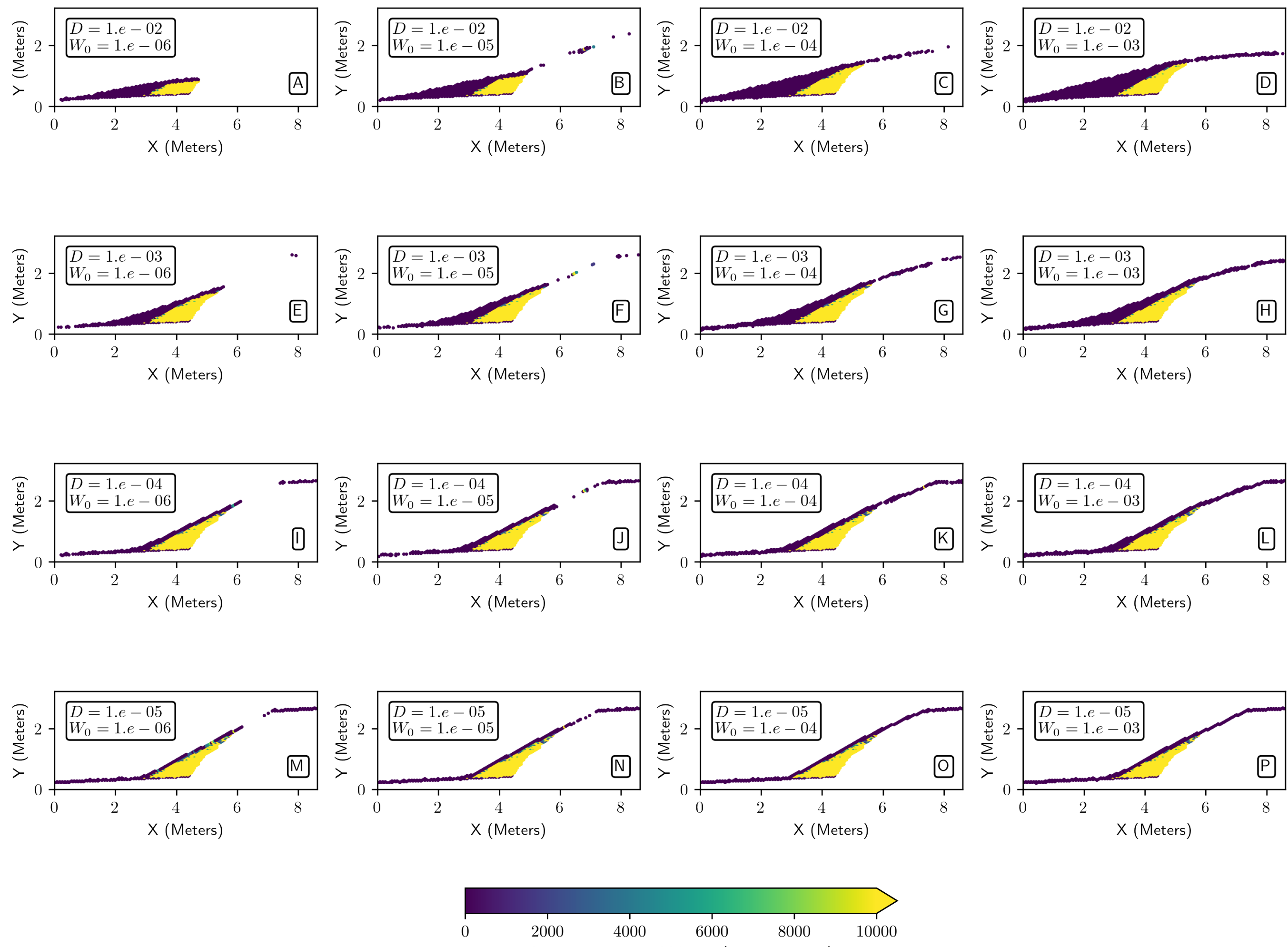

Average Transport Velocity (meter per year) 
Figure S35: Transport Velocity Sensitivity; 60-degree Fault; Lateral Collapse Rate $=1$.e-09
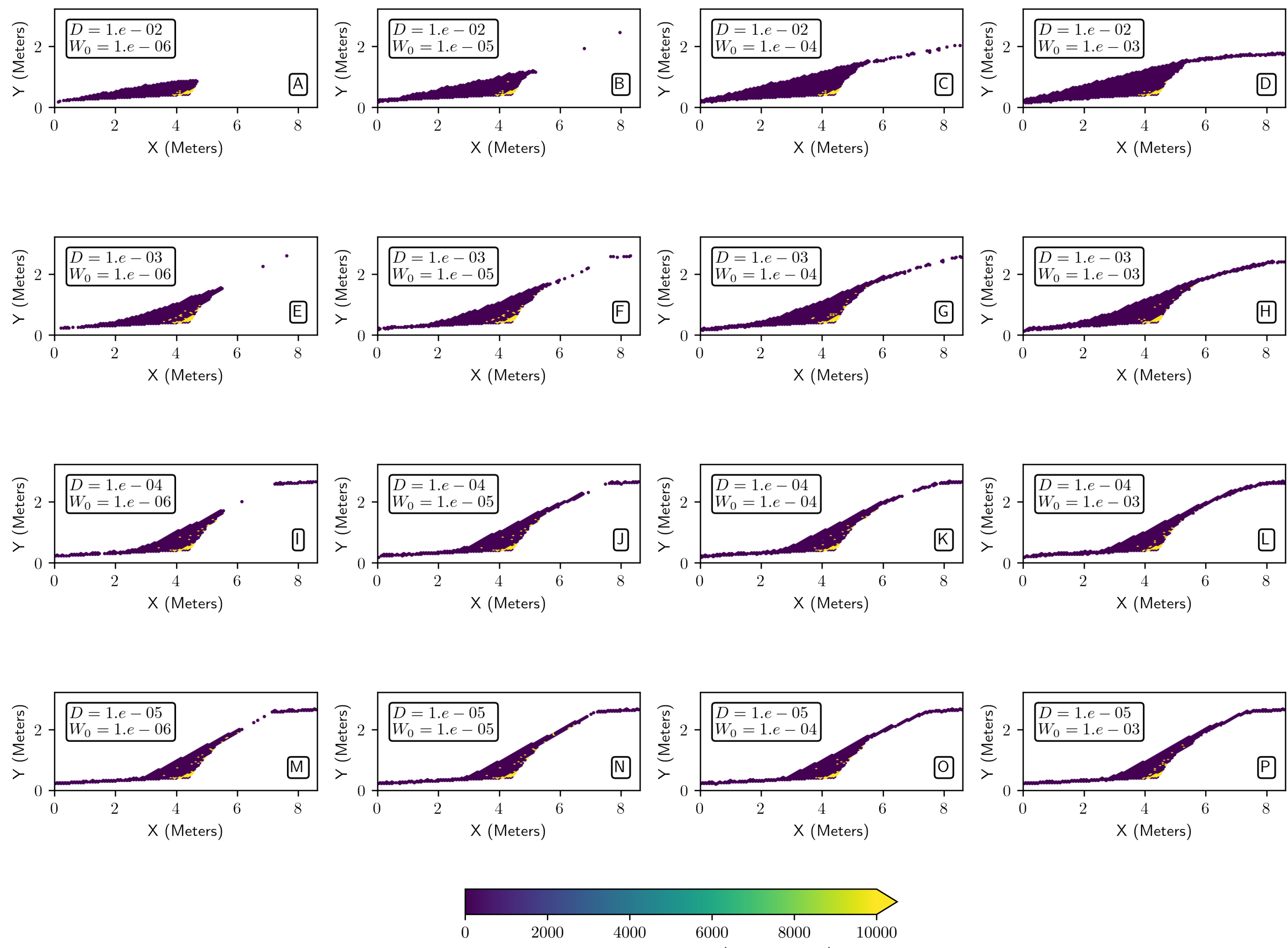

Average Transport Velocity (meter per year) 
Figure S36: Transport Velocity Sensitivity; 60-degree Fault; Lateral Collapse Rate $=1$. e-11
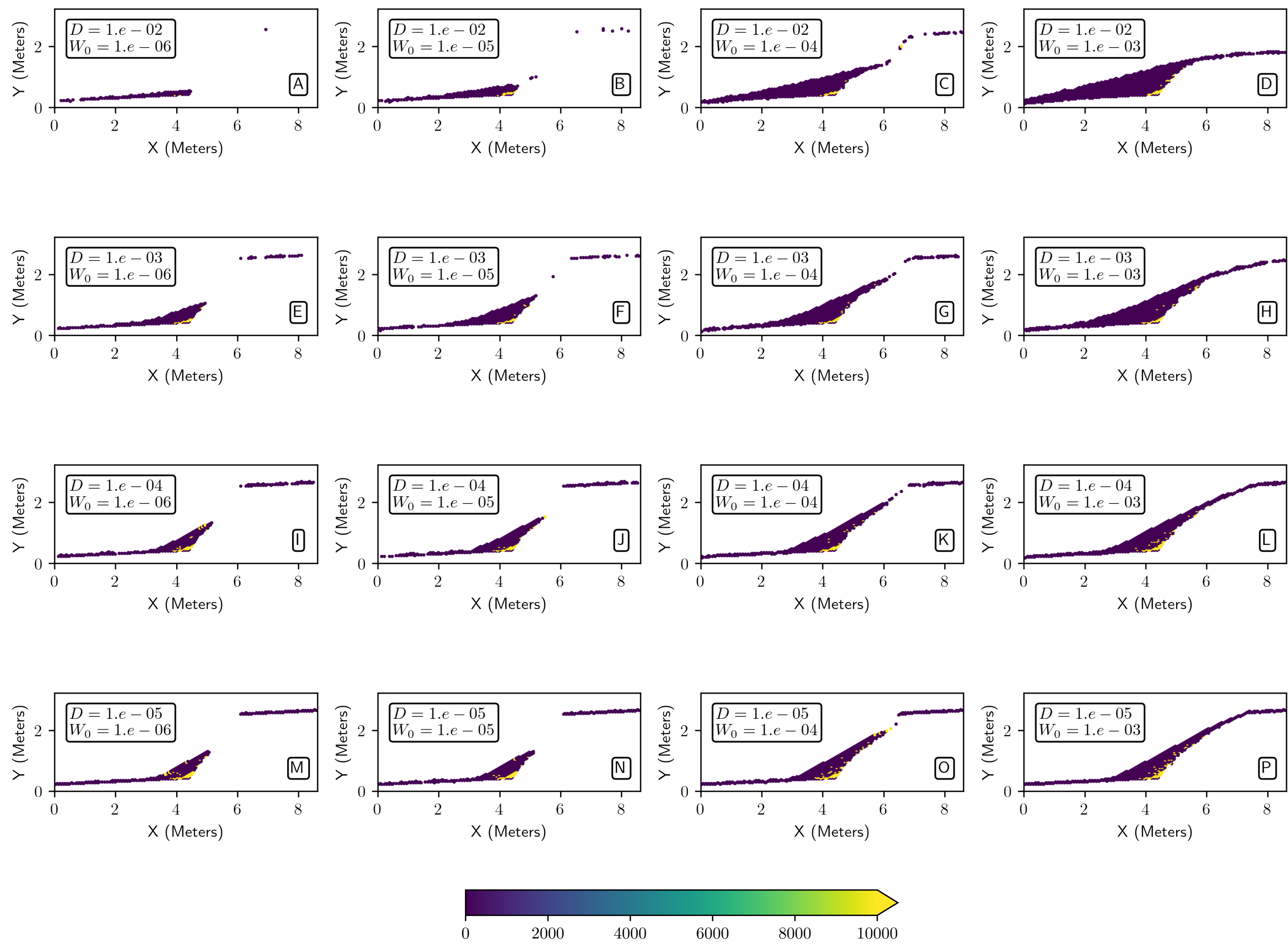

Average Transport Velocity (meter per year) 
Figure S37: Transport Velocity Sensitivity; 90-degree Fault; Lateral Collapse Rate $=1$. e-03
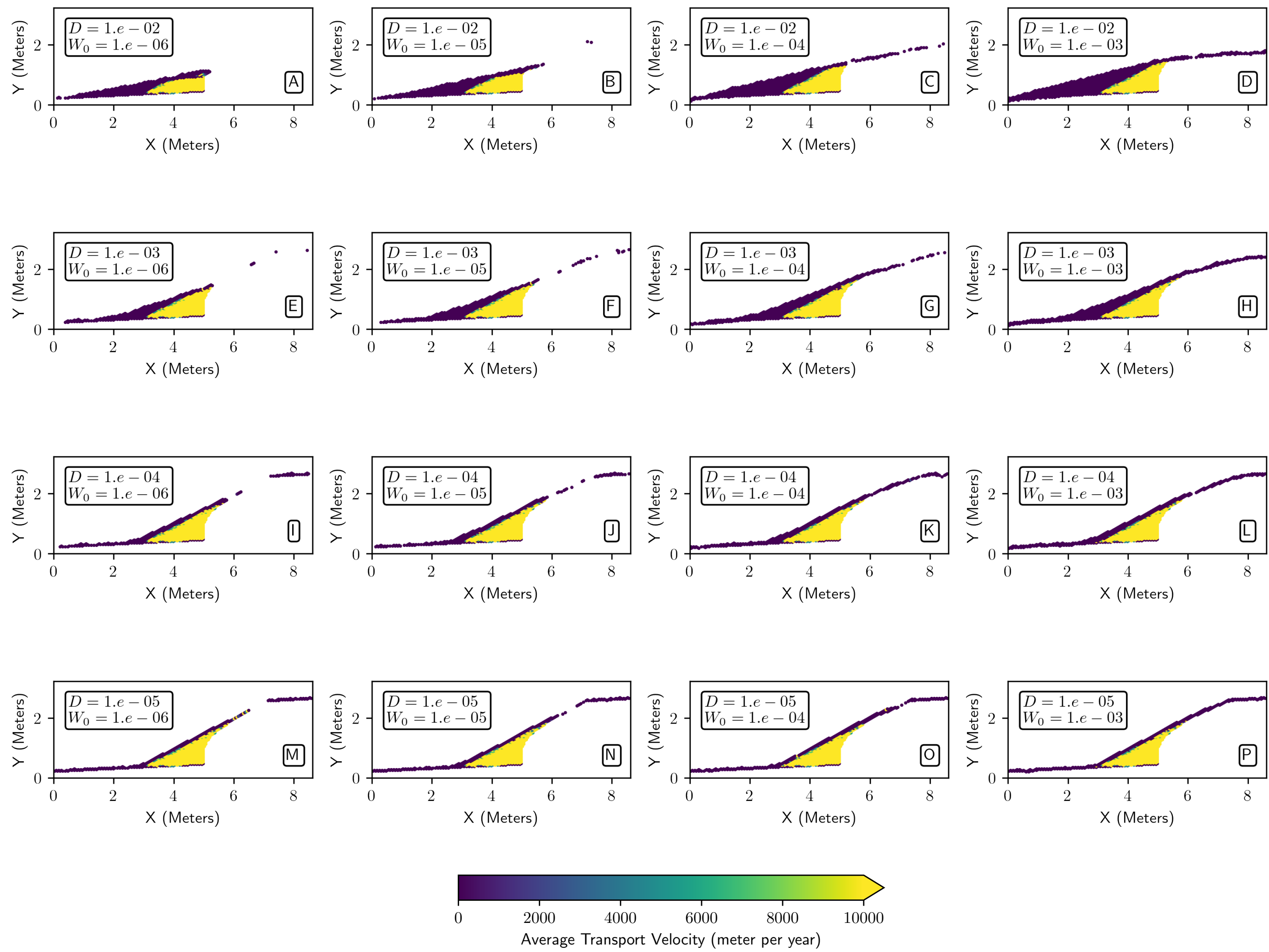
Figure S38: Transport Velocity Sensitivity; 90-degree Fault; Lateral Collapse Rate $=1$. e-05
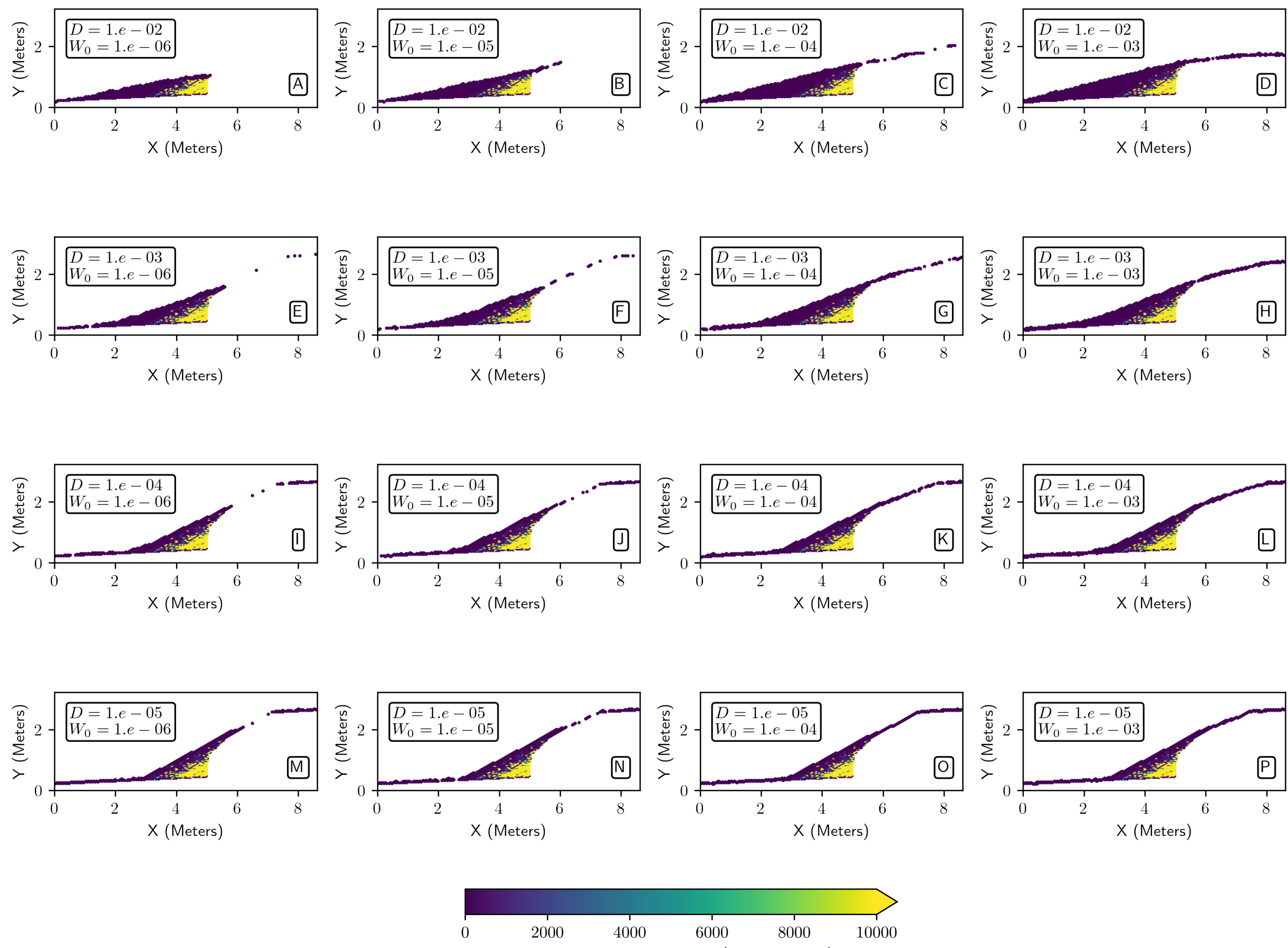

Average Transport Velocity (meter per year) 
Figure S40: Transport Velocity Sensitivity; 90-degree Fault; Lateral Collapse Rate $=1$. e-11
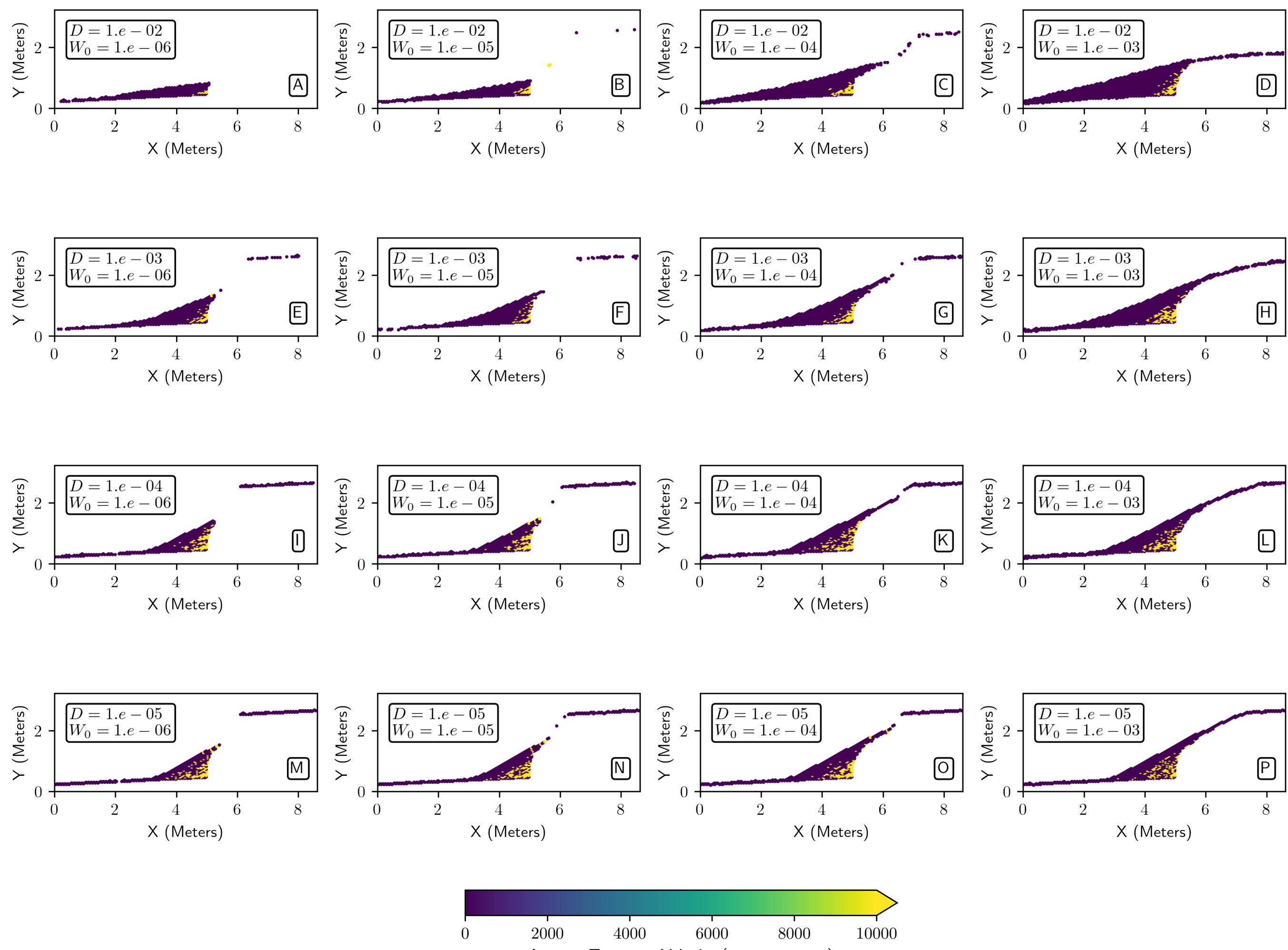

Average Transport Velocity (meter per year) 
Figure S43: Transport Time vs Transport Index; 60-degree Fault; Lateral Collapse Rate $=1$.e-09
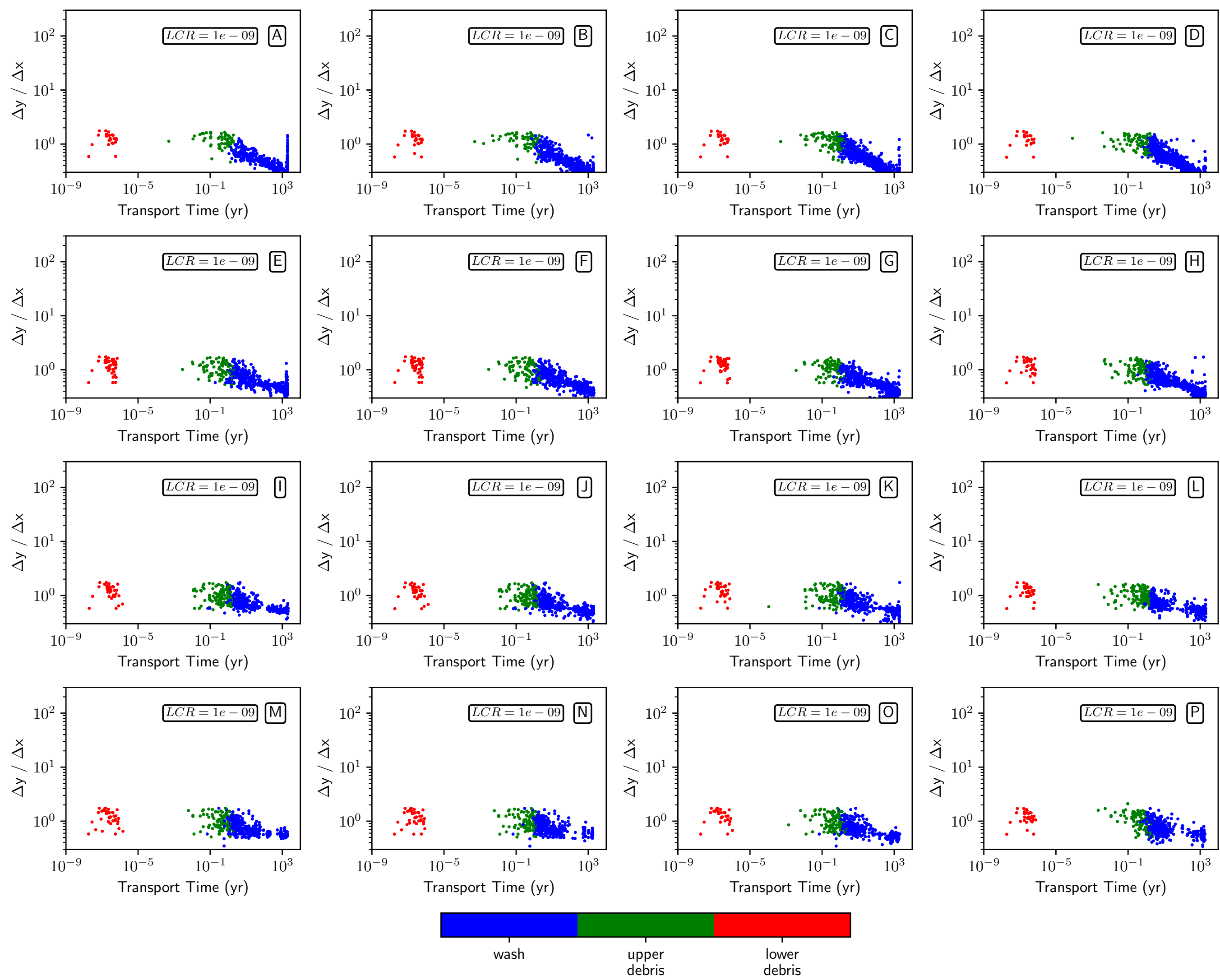

cell facies analog 
Figure S49: Linear Distance vs. Transport Index; 60-degree Fault; Lateral Collapse Rate $=1 . \mathrm{e}-03$
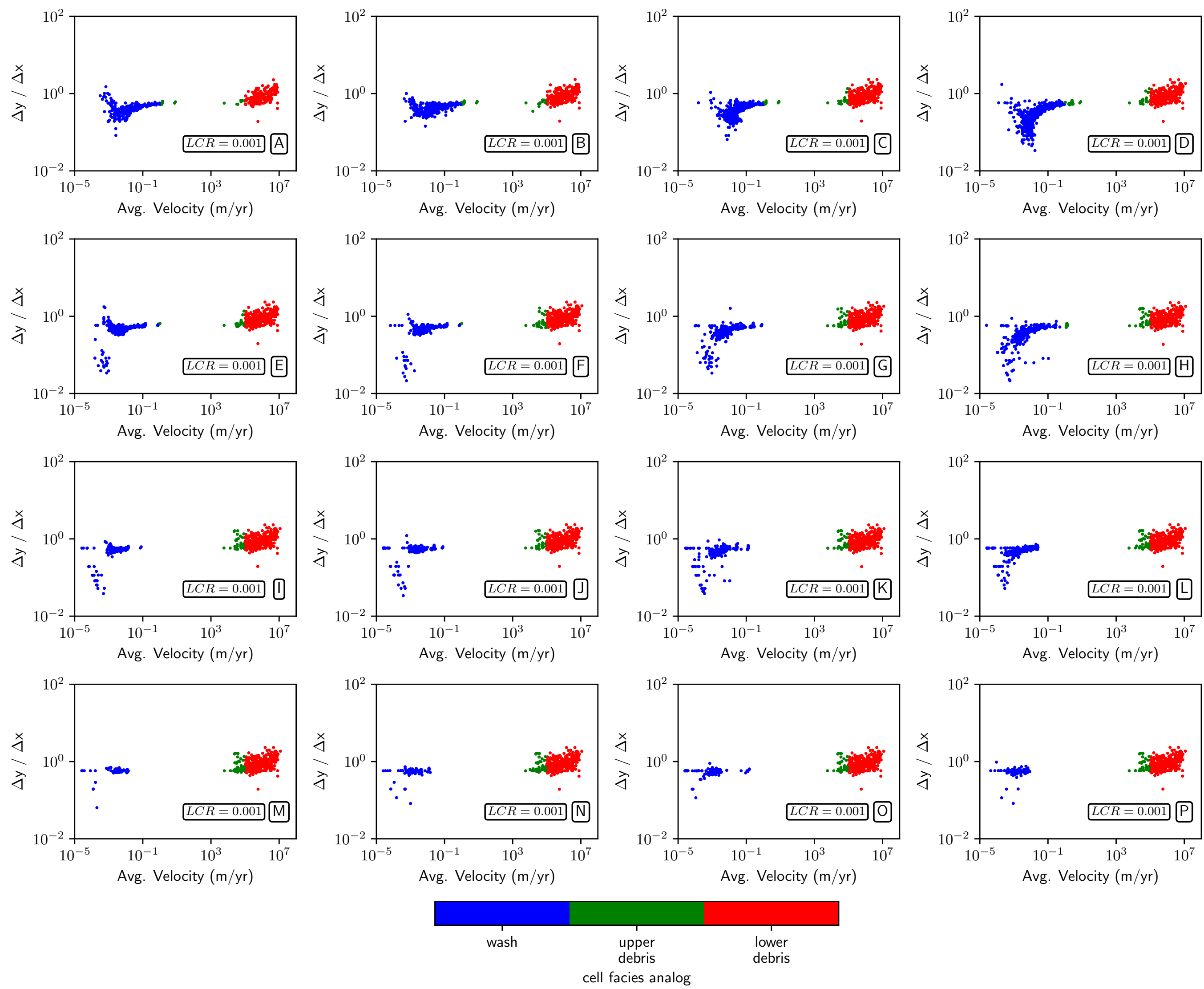
Figure S50: Linear Distance vs. Transport Index; 60-degree Fault; Lateral Collapse Rate $=1$.e-05
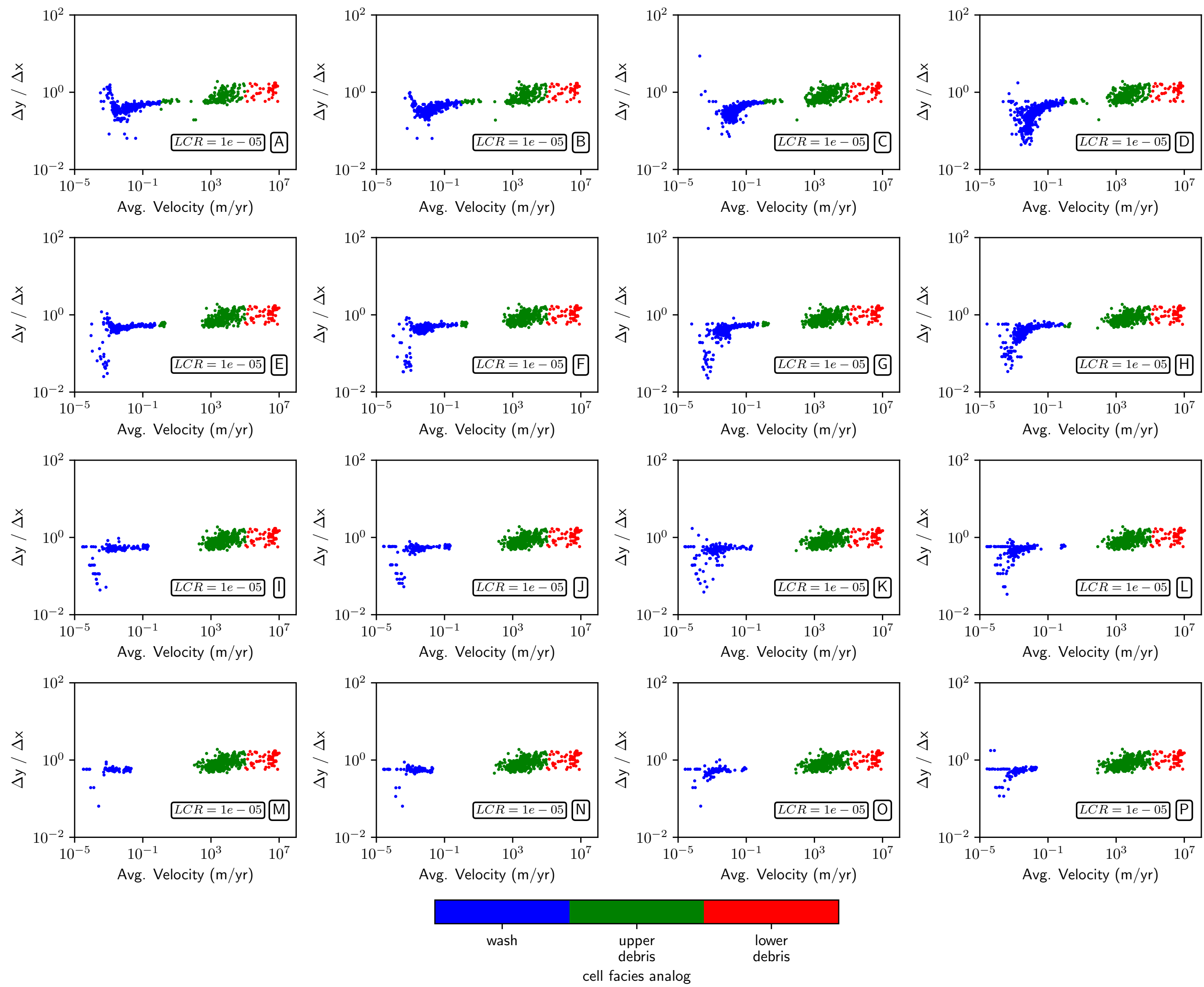
Figure S51: Linear Distance vs. Transport Index; 60-degree Fault; Lateral Collapse Rate $=1$.e-09
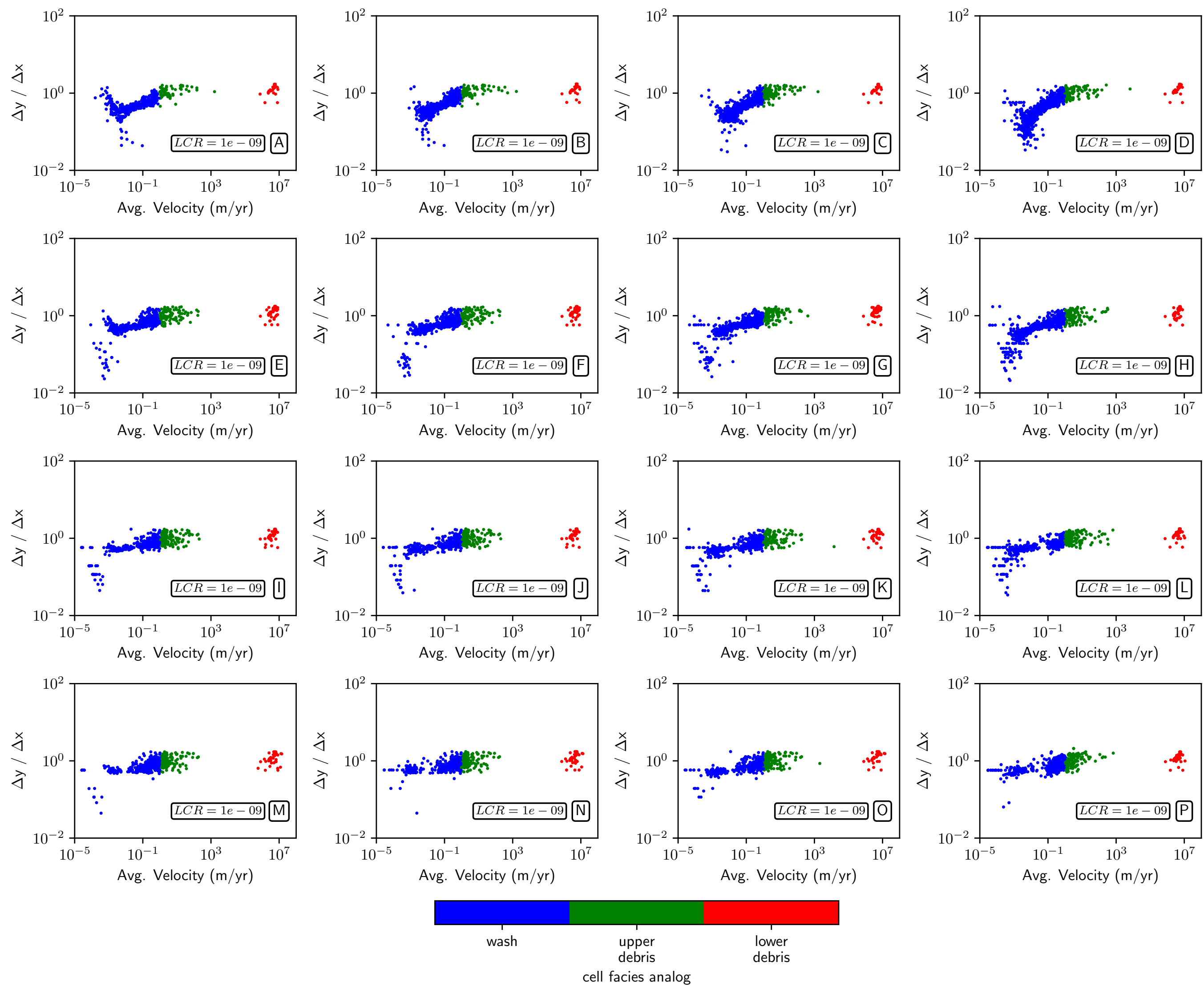
Figure S52: Linear Distance vs. Transport Index; 60-degree Fault; Lateral Collapse Rate $=1$.e-11
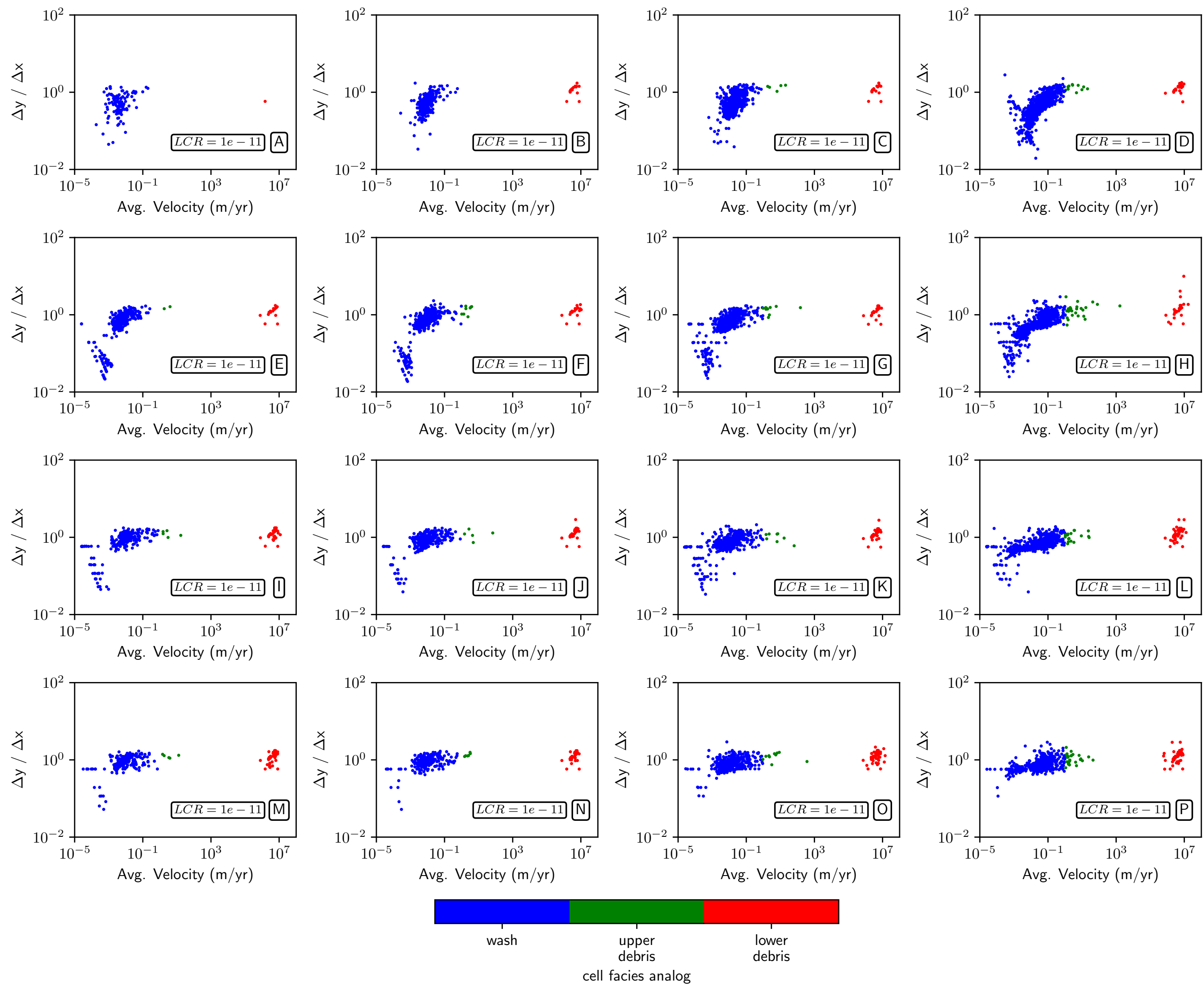
Figure S53: Linear Distance vs. Transport Index; 90-degree Fault; Lateral Collapse Rate $=1 . \mathrm{e}-03$
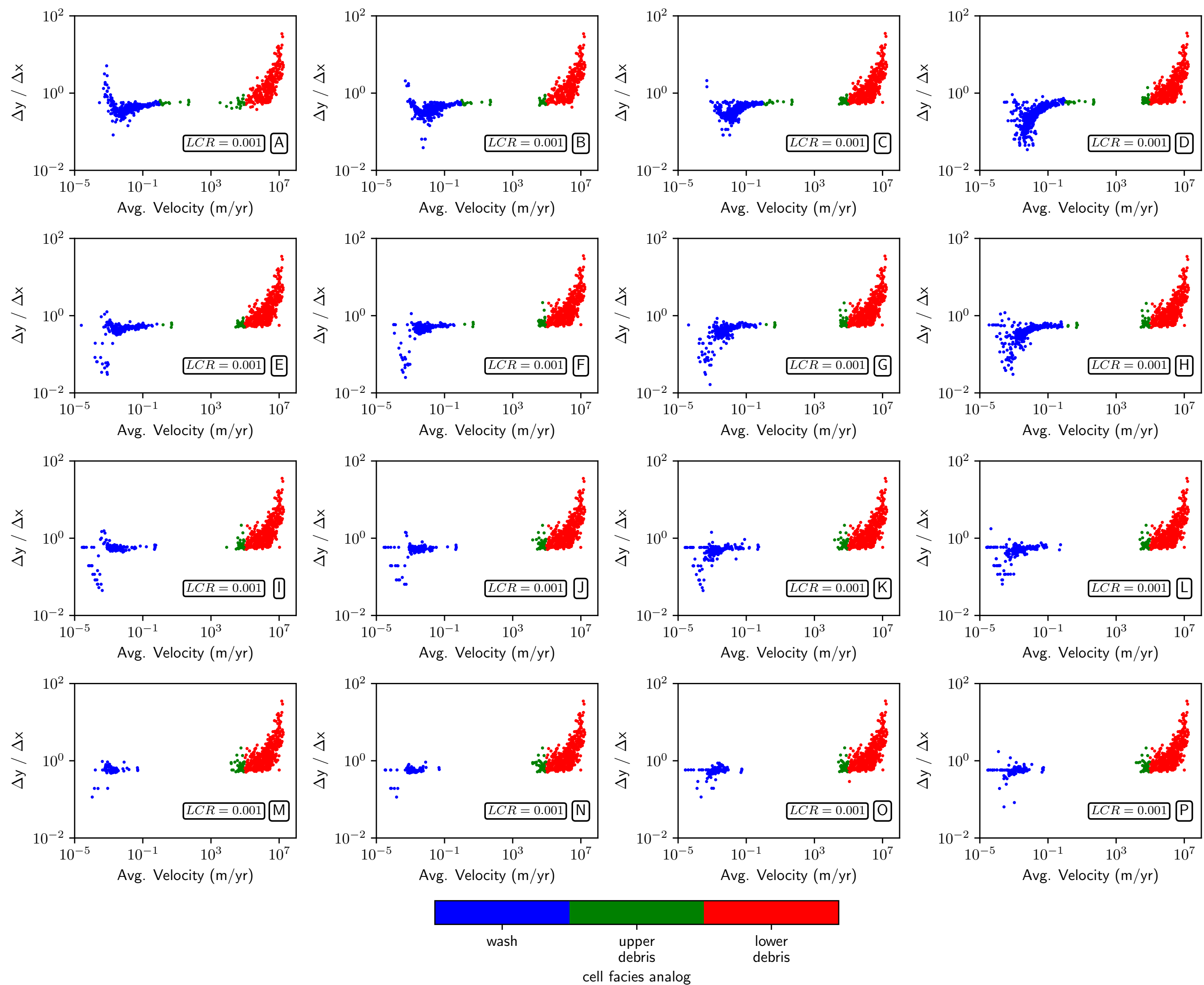
Figure S54: Linear Distance vs. Transport Index; 90-degree Fault; Lateral Collapse Rate $=1$. e-05
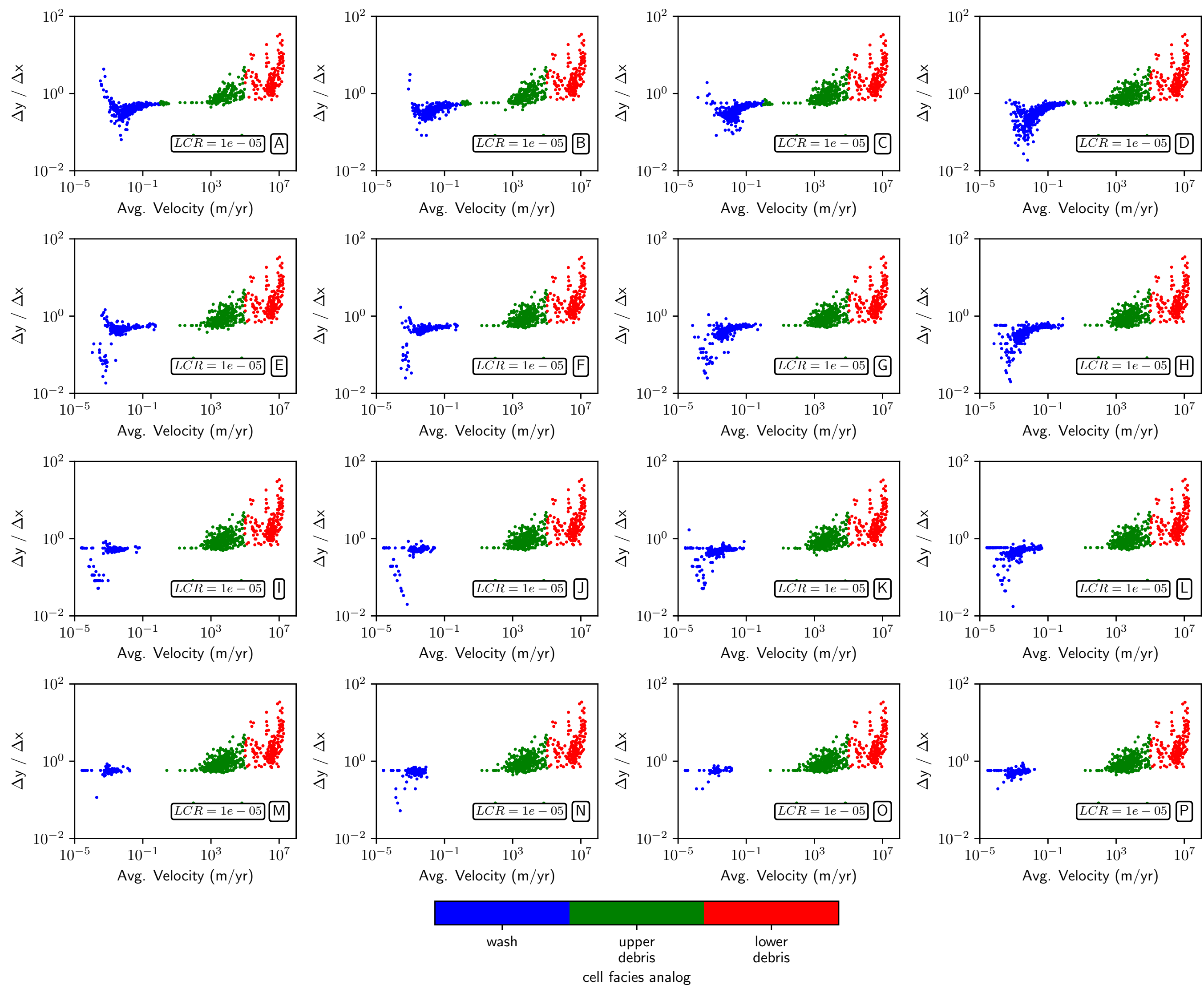
Figure S55: Linear Distance vs. Transport Index; 90-degree Fault; Lateral Collapse Rate $=1$. e-09
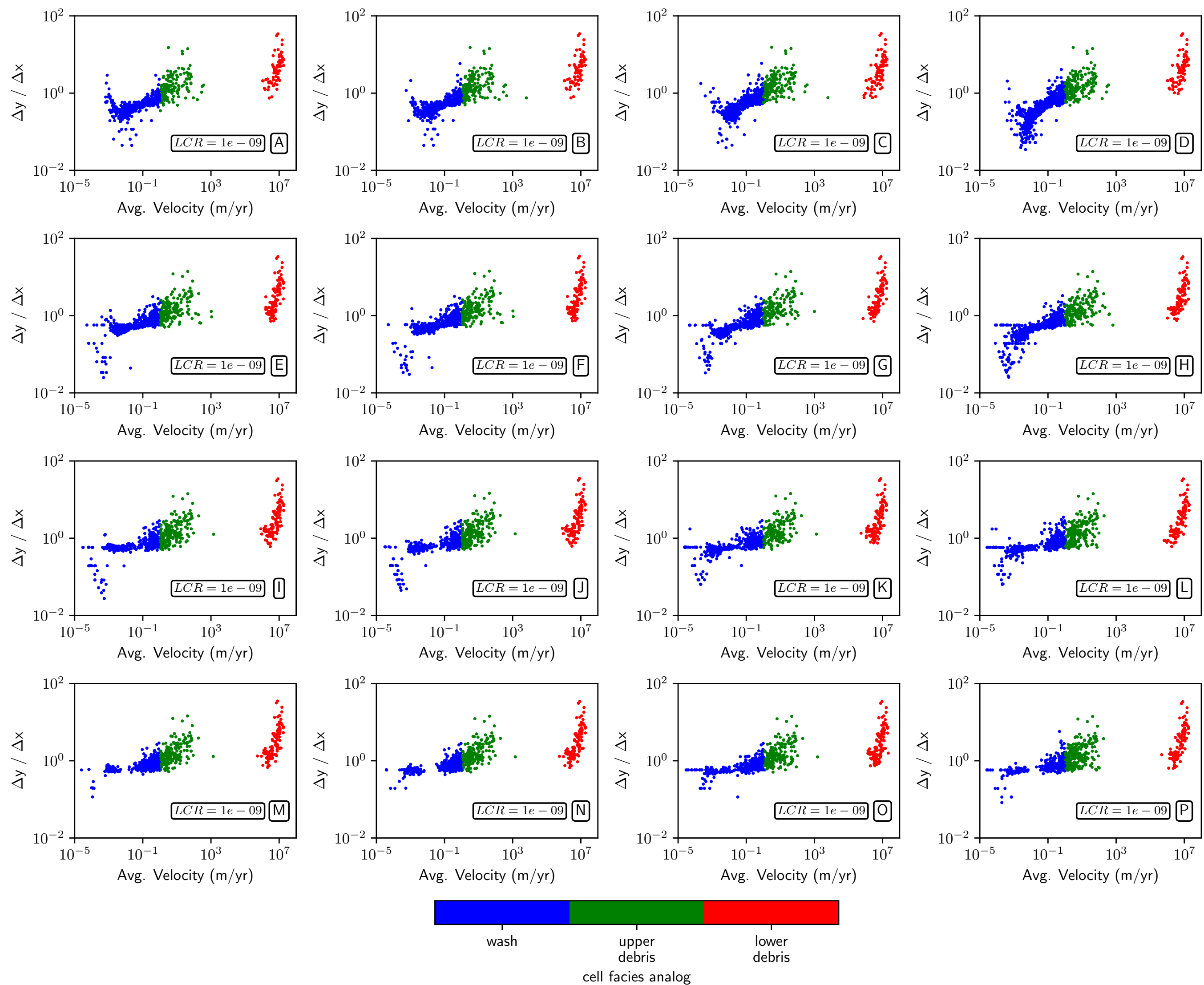
Figure S56: Linear Distance vs. Transport Index; 90-degree Fault; Lateral Collapse Rate $=1$.e-11
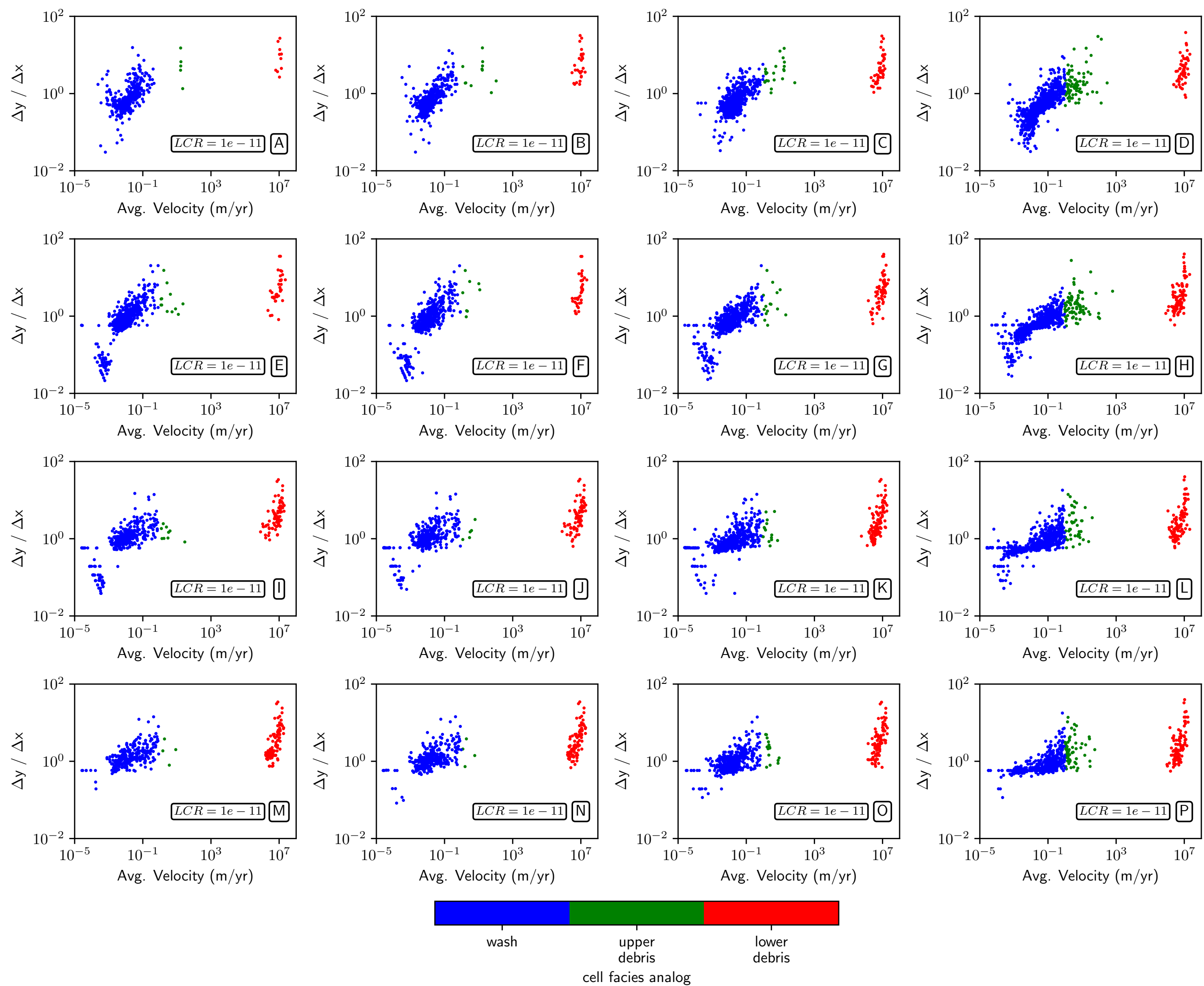
Figure S58: Linear Distance vs. Transport Index; 60-degree Fault; Lateral Collapse Rate $=1$. e-05
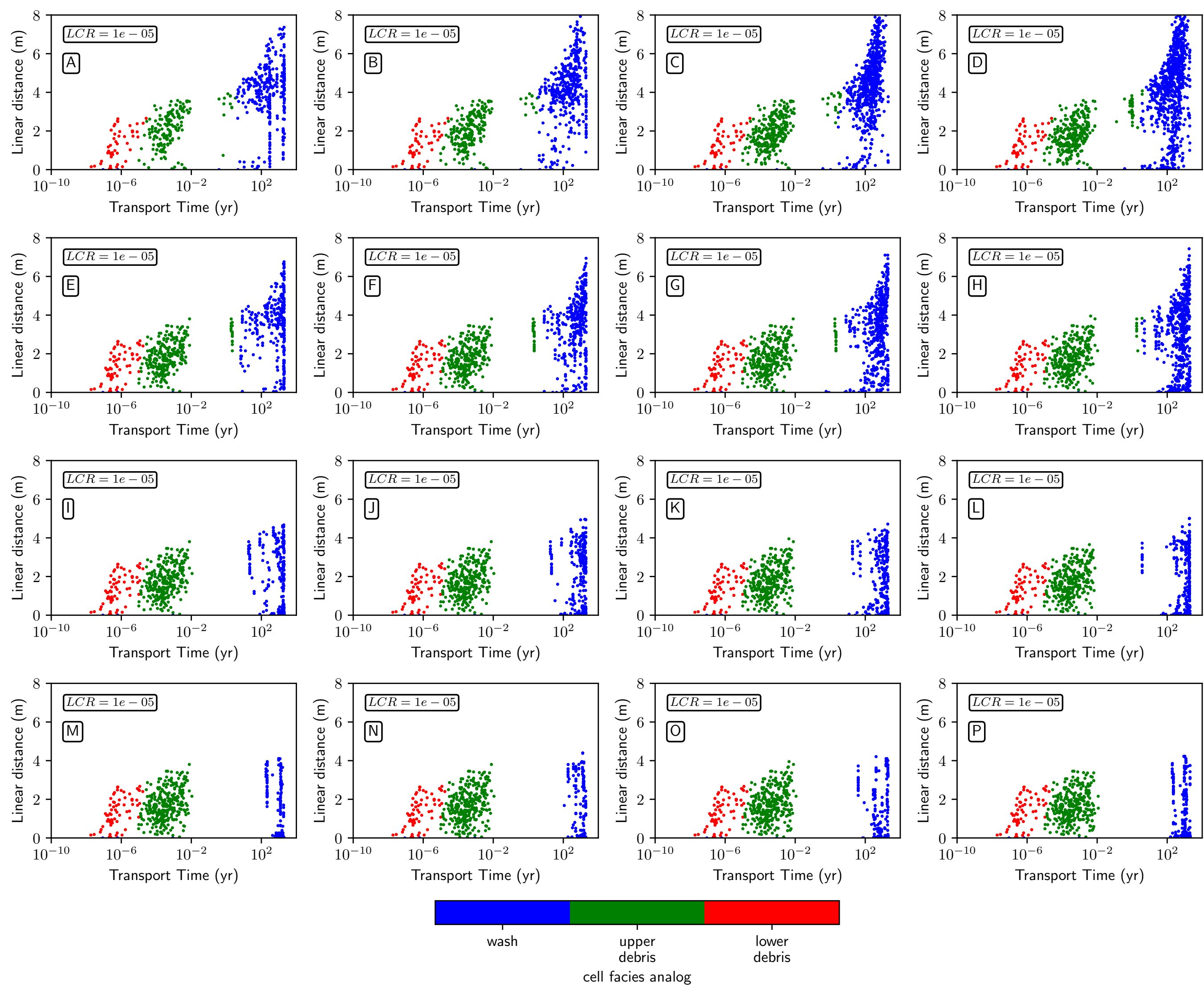
Figure S60: Linear Distance vs. Transport Index; 60-degree Fault; Lateral Collapse Rate $=1$.e-11
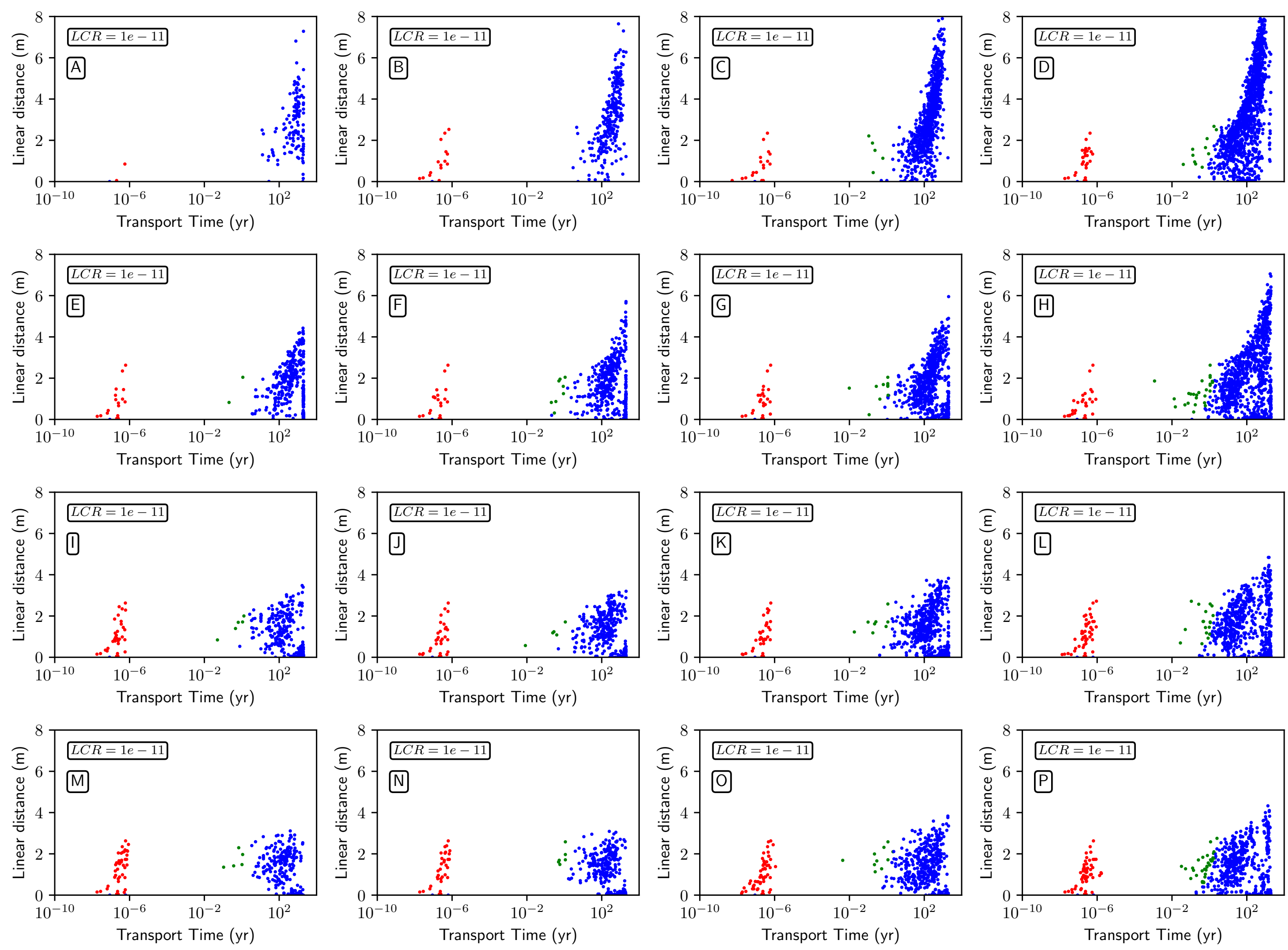
Figure S61: Linear Distance vs. Transport Index; 90-degree Fault; Lateral Collapse Rate $=1$. e-03
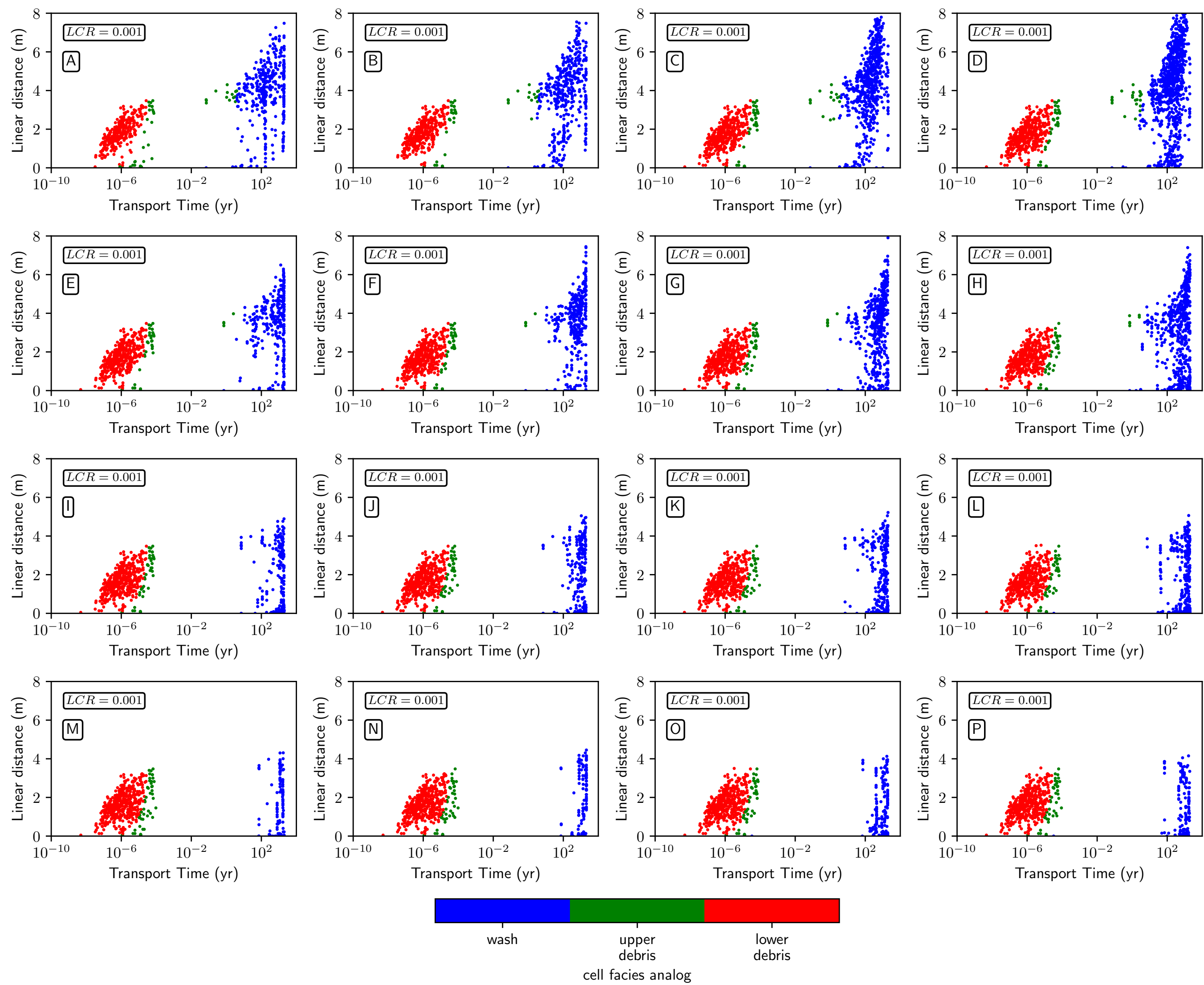
Figure S62: Linear Distance vs. Transport Index; 90-degree Fault; Lateral Collapse Rate $=1$. e-05
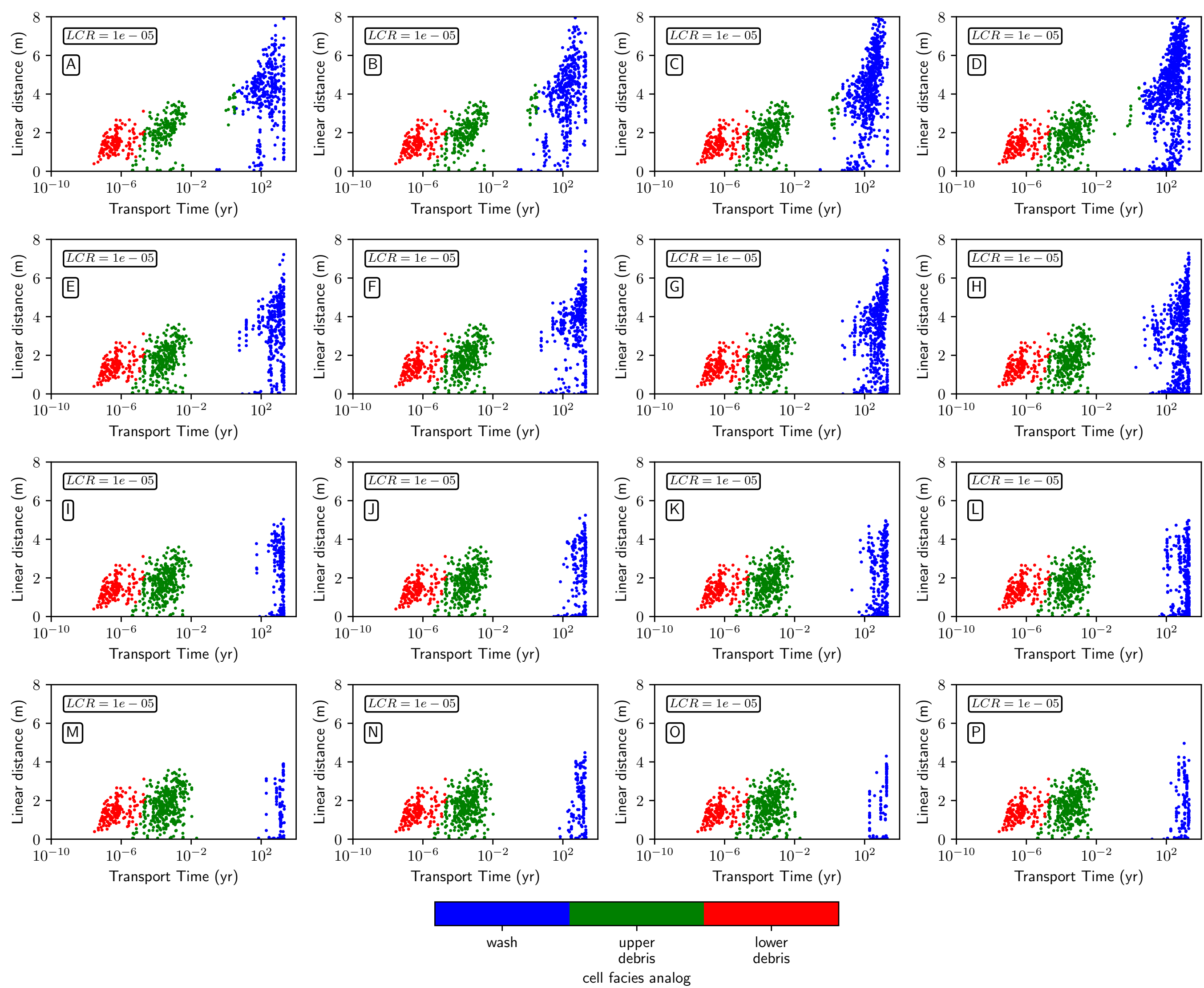
Figure S63: Linear Distance vs. Transport Index; 90-degree Fault; Lateral Collapse Rate $=1$.e-09
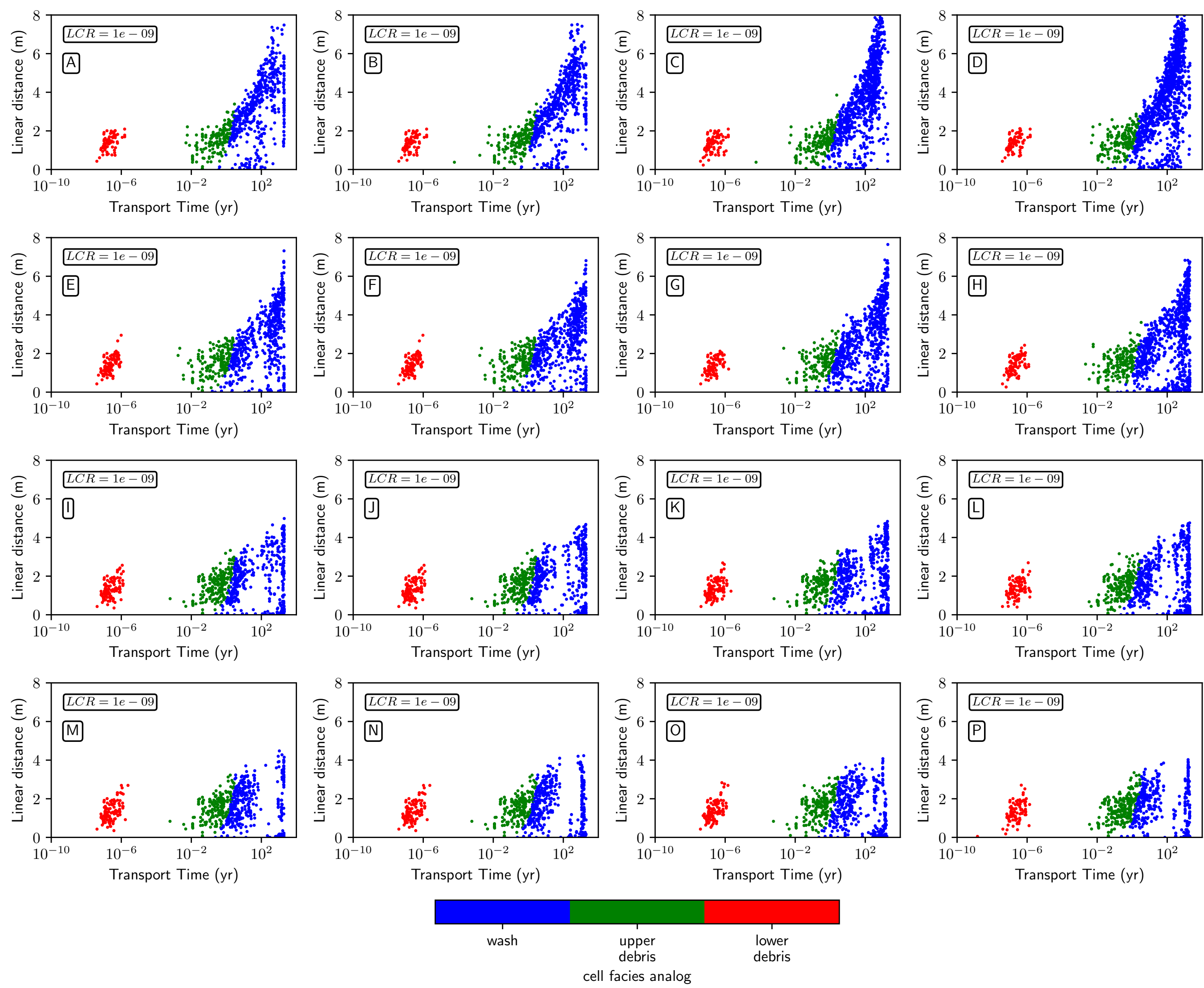
Figure S66: Cell Size Sensitivity; 90-degree Fault; Lateral Collapse Rate $=1$. e-05
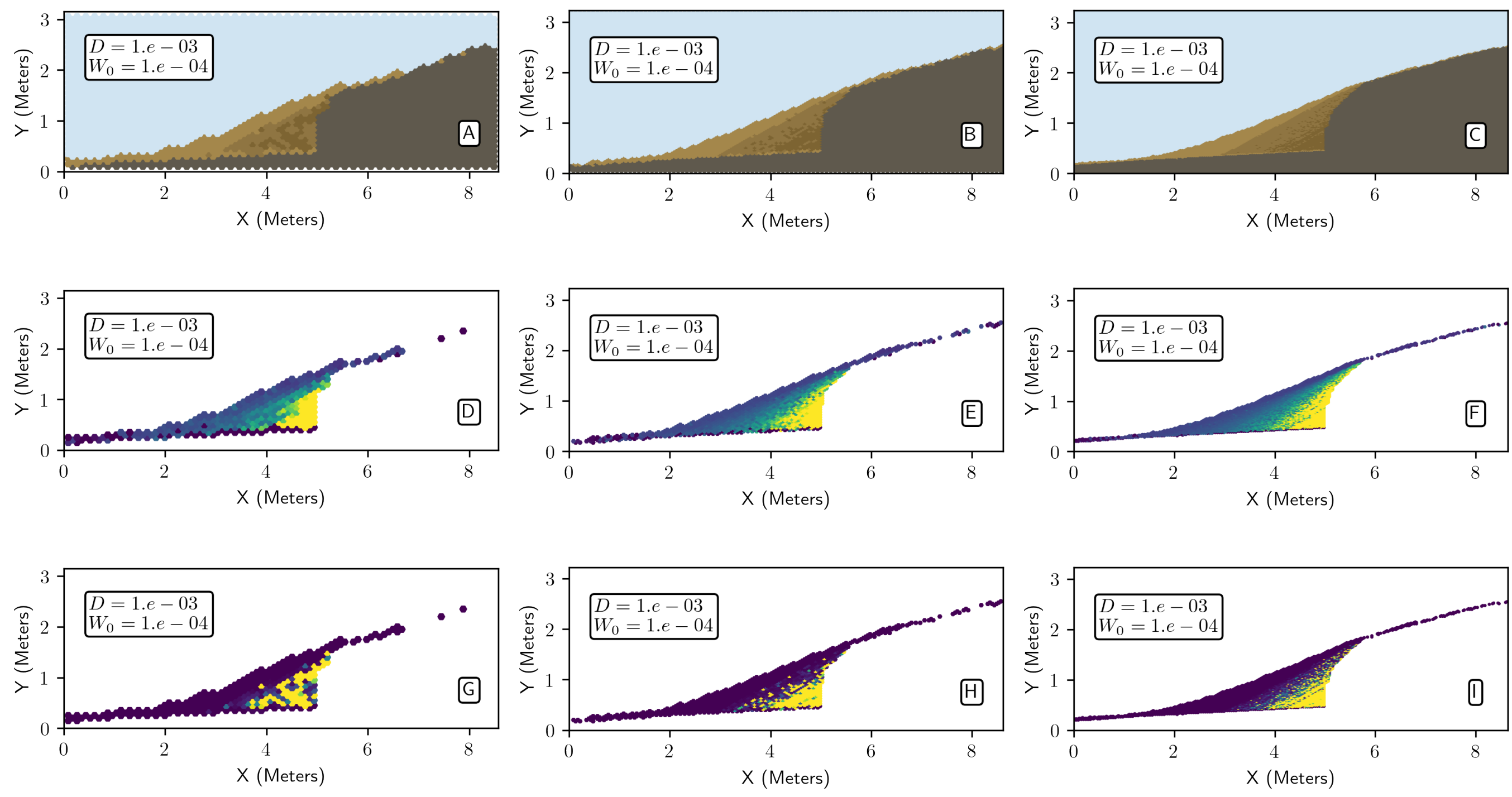